\title{
A computational model of CAR T-cell immunotherapy predicts leukemia patient responses at remission, resistance, and relapse
}

\author{
Authors \\ Lunan Liu ${ }^{1 \#}$, Chao Ma ${ }^{1,2 \#}$, Zhuoyu Zhang ${ }^{1}$, Weqiang Chen ${ }^{1,2,3,4^{*}}$
}

\author{
Affiliations \\ ${ }^{1}$ Department of Mechanical and Aerospace Engineering, New York University, Brooklyn, NY \\ 11201, USA; \\ ${ }^{2}$ Department of Biomedical Engineering, New York University, Brooklyn, NY 11201, USA; \\ ${ }^{3}$ Perlmutter Cancer Center, NYU Langone Health, New York, NY 10016, USA; \\ ${ }^{4}$ Department of Pathology, NYU Langone Health, New York, NY 10016, USA; \\ *Correspondence should be addressed to W. Chen (email: wchen@nyu.edu) \\ \# These authors contribute equally.
}

\begin{abstract}
Adaptive CD19-targeted CAR (Chimeric Antigen Receptor) T-cell transfer has become a promising treatment for leukemia. Though patient responses vary across different clinical trials, there currently lacks reliable early diagnostic methods to predict patient responses to those novel therapies. Recently, computational models achieve to in silico depict patient responses, with prediction application being limited. We herein established a computational model of CAR T-cell therapy to recapitulate key cellular mechanisms and dynamics during treatment based on a set of clinical data from different CAR T-cell trials, and revealed critical determinants related to patient responses at remission, resistance, and relapse. Furthermore, we performed a clinical trial simulation using virtual patient cohorts generated based on real clinical patient dataset. With input of early-stage CAR T-cell dynamics, our model successfully predicted late responses of various virtual patients compared to clinical observance. In conclusion, our patient-based computational immuno-oncology model may inform clinical treatment and management.
\end{abstract}

\section{MAIN TEXT}

\section{Introduction}

Anti-CD19 CAR (Chimeric Antigen Receptor) T-cell therapy is a promising immunotherapy for B cell acute lymphoblastic leukemia (B-ALL) $(1,2)$. Yet, clinical B-ALL cases demonstrated stochastically response and non-response to CAR T-cell therapy (3). For example, continuous/complete remission (CR) can be achieved in $70-90 \%$ of pediatric and adult patients, while long-term studies showed $30-60 \%$ of patients encounter either CD19-positive (CD19 $)$ or CD19-negative (CD19-) relapse (4). Although various CAR T-cell products and combinational therapies have been tested in different clinical trials to improve patient response $(4,5)$, numerous questions remain unanswered to systematically understand the causes of the varied therapeutic 
responses. Thus, new clinical models that can predict patient responses to CAR T-cell treatment is critically desired to screen the most effective treatment protocol for individual patients.

Recently, computational models, based on empirical rationales, mathematic simulations with input of clinical data, provide valuable tools for in silico and systematical analysis of key biological mechanisms and patient responses in cancer immunotherapy $(6,7)$. Up-to-date, computational modeling of CAR T-cell therapy arises in early stages with applications of model-informed response prediction being limited. For example, a multiscale physiologically based pharmacokinetic-pharmacodynamic model had been developed for a quantitative study of relationship between CAR-affinity, antigen abundance, tumor cell depletion and CAR T-cell expansion using data collected from xenograft mouse models (8). Other approaches focus mostly on modeling factors underlying CAR T-cell dynamics, such as ecological dynamics regulated CAR T-cell explain expansion (9) and exhaustion (10), signaling-induced cell state variability (11), and CAR T-cell expansion due to lymphodepletion and competitive growth between CAR T-cell and normal T-cell (12). Lately, Liu et al. developed a model to characterize clinical CAR T-cell kinetics across response status, patient populations, and tumor types, yet only in a retrospective manner (13). However, these computational models typically fail to provide a collective analysis and effective interpretation of clinical trial data from different clinical studies to reveal the key cellular mechanisms underlying the heterogeneous patient outcomes observed in different clinical trials. Critically, a clinical data-based prognostic model that can predict patient responses to CAR T-cell treatment at early stage is largely absent.

In the present study, we developed a mathematical framework of CAR T-cell therapy structured with a matrix of numerical differential equations for a quantitatively study and in silico modeling of key biological mechanisms in CAR T-cell therapy, such as leukemia cell growth and apoptosis, CAR T-cell activation, expansion, and cytotoxic efficiency, and CD19 antigen mediated relapse mechanisms. After calibration and validation with clinical data from 209 leukemia patients, our computational model revealed key determinants that depicted the heterogeneous clinical responses between the responders, non-responders, and patients with CD $19^{+} / \mathrm{CD} 19^{-}$relapse. A useful model that can provides accurate predictions requires large representative datasets for validation. Clinical trial simulation studies the effects of a therapy in virtual patient cohorts using mathematical models of physiological system, which to some extent enlarges sampling for clinical trials and full range of mechanistic testing $(14,15)$. Incorporating this concept, we performed a clinical trial simulation of CAR T-cell therapy using virtual patient cohorts generated based on real clinical patient dataset. With input of early-stage clinical and in silico generated virtual patient data, our model successfully predicted the late therapeutic outcomes of most patients under CAR T-cell treatment, which may inform clinical treatment and guide clinical trials of personalized CAR T-cell therapy.

\section{Results}

\section{A computational model of CAR T-cell immunotherapy}

To construct a computational model of CAR T-cell therapy that reproduces the pathophysiological processes and immunological interactions, we framed a matrix of numerical differential equations (Details see 'Model construction' in Methods) and calibrated the model using the stochastic approximation expectation maximization (SAEM) algorithm for nonlinear mixed-effect modeling (NLME), as implemented in Monolix (Lixoft, France). To fit and calibrate our model, we searched and collected clinical data of 209 B-ALL patients from 10 clinical trials of anti-CD19 CAR T-cell therapies and sampled into 32 groups (Details see 'Collecting and processing clinical data' in 
Methods). Of note, only statistic values like medians were available for several trials (Supplemental Table S1-4). The clinical data were assigned into different patient cohorts, i.e., $\mathrm{CR}$, non-response (NR), CD19 ${ }^{+}$relapse and CD19- relapse (Figure 1), based on the flow cytometry and quantitative polymerase chain reaction (qPCR) monitoring of CAR T-cell in the blood, as well as morphological testing of leukemia burden in the bone marrow. To minimize the variation across different batches and clinical trials, we unified and transformed all the clinical data at a scale equivalent to the bone marrow level (Details see 'Collecting and processing of clinical data' in Methods). Model fitting and parameterization processes is provided accordingly (Details see 'Parameter estimation' in Methods). For a dataset including different individuals, SAEM firstly fits the data as a group and estimate parameters on population level (population level parameters). After that, random effect is adopted to estimate the parameters of each individual (individual level parameters) based on population level parameters.

We firstly calibrated the proposed computational model with clinical data of CAR T-cell and tumor burden of $148 \mathrm{CR}$ patients (Supplemental Table S1, Supplemental Figure S1), and simulated the dynamic behaviors of CAR T-cell and tumor cell during the treatment. After being activated by the CD $19^{+}$B-ALL cells, CAR T-cell rapidly expanded and reached the peak within the first 1-2 weeks, and then gradually decreased after tumor cells were rapidly depleted. The results show a great correlation between clinical statistics and simulation data (Figure $\mathbf{2 A} \& \mathbf{B}$ ). We found that the peak value of CAR T-cell during treatment increased as initial tumor burden increased, in consistent with clinical observation (Figure 2C). This is largely due to the rapid in vivo CAR T-cell expansion stimulated by $\mathrm{CD} 19^{+}$tumor cell as verified by the real-time simulation results with increasing initial tumor burden (Figure 2D). Similar correlation was seen between the peak value and activation rate of CAR T-cell (Figure 2E). Moreover, the day when CAR T-cell peaked is correlated to the day when patient achieved minimal residual disease ( $\mathrm{MRD}^{-}$, tumor burden $<0.01 \%$ ) (Figure 2F).

In parallel, we calibrated the model with clinical data of $24 \mathrm{NR}$ patients to model the scenario of non-responders, which again confirmed its validity (Figure 3A\&B, Supplemental Figure S2, Supplemental Table S2). For instance, significant differences were reproduced as observed in CR and NR patients in terms of CAR T-cell and tumor cell dynamics (Figure 3C). In particular, the peak value and AUC28 (area under the curve from day 0 to day 28, a commonly-used clinical marker to evaluate the expansion and function of CAR T) of CAR T-cells in NR patients were less than those of CAR T-cells in CR patients at population level. Similar trends were further confirmed at individual level by experimental and simulation data (Figure 3D\&E). To understand such difference, we further ran a sensitivity analysis of population level parameters and found that those related to CAR T-cell functionality, such as growth rate $r_{\mathrm{TA}}$, killing rate $e$, activation rate $k_{\mathrm{A}}$, and apoptosis rate $l_{\mathrm{TA}}$, critically influence CAR T-cell therapy outcomes (Supplemental Figure S3). Our model indicated that the median values of these factors significantly differed between CR and NR patients (Figure 3F-I). CAR T-cell in CR patients but not those in NR patients generally have higher growth rate $r_{\mathrm{TA}}$, killing rate $e$, activation rate $k_{\mathrm{A}}$ but lower apoptosis rate $l_{\mathrm{TA}}$, suggesting an impaired CAR T-cell functionality in NR patients. These results together demonstrate the capability of our computational model to recapitulate the clinical dynamics during CAR T-cell therapy.

In silico modeling reveals distinct $\mathrm{CAR}$ T-cell patterns in $\mathrm{CD}^{+}{ }^{+}$and $\mathrm{CD}^{-}{ }^{-}$relapse scenarios In addition to those achieving continuous remission and showing non-response, some patients showed either $\mathrm{CD} 19^{+}$or $\mathrm{CD} 19^{-}$relapse after CAR treatment (6). To understand the heterogeneity 
between these two main relapse scenarios, we recalibrated the model with respective clinical data (Figure 4A\&B, Supplemental Figure S4\&S5A-C, Supplemental Table S3\&S4). As shown by the individual level-calibration results, our computational model successfully mimicked the relapse progress at different days of relapse (Figure 4C\&D). Furthermore, we found that the day of $\mathrm{CD}_{19^{+}}$relapse is positively related to the AUC28 of CAR T-cell (Figure 4E), whereas this is not the case for CD19- relapse scenario (Figure 4F). To better explain this distinct pattern, we defined CAR T-cell function factor $F_{\mathrm{T}}$,

$$
F_{\mathrm{T}}=\frac{r_{\mathrm{TA}} \times e \times k_{\mathrm{A}}}{l_{\mathrm{TA}}}
$$

to quantitatively describe the overall CAR T-cell functionality consisting of growth, cytotoxicity and persistence where $r_{\mathrm{TA}}$ is the growth rate, $e$ is the killing rate, $k_{\mathrm{A}}$ is the activated rate, and $l_{\mathrm{TA}}$ is the apoptosis rate of CAR T-cell. Simulation results demonstrated that the increase of $F_{\mathrm{T}}$ prolonged the day of CD $19^{+}$relapse (Figure 4G), but not that of CD19- relapse (Supplemental Figure S5D). Such difference can be partially explained by the presence of CD19- B-ALL cells before infusion of CAR T-cell and the following selective pressure by CAR T-cell (4). Besides, the genetic mutation causing loss of surface expression of CD19 and the bystander killing of CAR T-cell may further determined the progression of $\mathrm{CD} 19^{-} \mathrm{B}-\mathrm{ALL}$ cells $(16,17)$. To integrate these two effects, we therefore defined the negative relapse factor $F_{\mathrm{NegR}}$,

$$
F_{\mathrm{NegR}}=k_{\mathrm{m}} k_{\mathrm{b}}
$$

where $k_{\mathrm{m}}$ is the mutation factor considering the rate of gene mutation like alternative slicing with loss of exon 2 and the probability of lineage switch, and $k_{\mathrm{b}}$ is the bystander killing scaling factor depicting the killing efficacy of CAR T to CD19- tumor cells comparing with to CD19 ${ }^{+}$ones. As a result, $F_{\text {NegR }}$ demonstrated a high correlation with the day of CD19- relapse, confirming its validity in depicting the mechanism of CD19- relapse (Figure $4 \mathbf{H}$ ). Together, our results reveal a distinct pattern of relapse across the $\mathrm{CD} 19^{+}$and $\mathrm{CD}^{-} 9^{-}$scenarios.

\section{Key determinants underlie heterogeneous responses to CAR T-cell therapy}

To understand the key factors determining the heterogeneous responses to CAR T-cell therapy, we systematically and comparatively analyzed the clinical data, such as the initial tumor burden and peak value of CAR T-cell in CR, NR, CD19 ${ }^{+}$relapse and CD19- relapse patients after CAR T-cell therapy. There was no significant difference $(\mathrm{P} \geq 0.398)$ was observed in initial tumor burden among patients with different responses (Supplemental Figure S6A), suggesting that using initial tumor burden alone cannot determine CAR T-cell response. In parallel, we calculated the peak value and AUC28 of CAR T-cell for the four kinds of responses at the population level and found that $\mathrm{CR}$ and $\mathrm{CD} 19^{-}$relapse patients demonstrated higher values than did CD19 ${ }^{+}$relapse patients, whereas NR patients showed the minimum values (Figure 5A). We then tuned the values of the individual parameters $\left(r_{\mathrm{TA}}, e, k_{\mathrm{A}}\right.$, and $\left.l_{\mathrm{TA}}\right)$ of CAR T-cell function factor $F_{\mathrm{T}}$ in silico and found that as expected the $F_{\mathrm{T}}$ parameter regulated the therapeutic effect of CAR T-cell treatment (Supplemental Figure S6B\&C). These results together indicated the potential of $F_{\mathrm{T}}$ in differentiating these outcomes, such as $\mathrm{CR}, \mathrm{CD} 19^{+}$relapse and $\mathrm{NR}$ after CAR T-cell therapy, though this was not the case for $\mathrm{CD}^{-} 9^{-}$relapse (Figure 5B). Furthermore, we scaled the population level calibrated parameters in $F_{\mathrm{T}}$ of different responses $\left( \pm 25 \%\right.$ for $\mathrm{CR}, \pm 10 \%$ for $\mathrm{CD} 19^{+}$relapse, $\pm 5 \%$ for NR), which again confirmed the usefulness of $F_{\mathrm{T}}$ (Figure 5C). Based on the clinical response and the distribution of $F_{\mathrm{T}}$ of patients (Figure 5B), the probability distribution of $F_{\mathrm{T}}$ of different responses were fitted with the MATLAB Distribution Fitter Toolbox (Supplemental 
Figure S6D). According to such probability distribution, the occurrence probabilities of CR, $\mathrm{CD} 19^{+}$relapse or $\mathrm{NR}$ at certain $F_{\mathrm{T}}$, i.e., $P_{i}\left(F_{\mathrm{T}}\right)$ can be determined as

$$
P_{i}\left(F_{\mathrm{T}}\right)=\frac{p_{i}\left(F_{\mathrm{T}}\right)}{\sum_{j=\mathrm{CR}, \mathrm{CD} 19^{+}, \mathrm{NR}} p_{j}\left(F_{\mathrm{T}}\right)},\left(i=\mathrm{CR}, \mathrm{CD} 19^{+}, \mathrm{NR}\right)
$$

where $p$ is the probability distribution of different responses (Supplemental Figure S6C). We found that as $F_{\mathrm{T}}$ increased, the most likely response to CAR T-cell therapy changed from NR to CD $19^{+}$relapse, and further to CR (Figure 5D). Besides, the distribution of scaled $F_{\mathrm{T}}$ (Figure 5C) fell into the range of corresponding response (Figure 5D). Similarly, since $F_{\mathrm{T}}$ cannot tell the characteristic of CD19- relapse, we found instead that $F_{\mathrm{NegR}}$ determined the efficacy of CAR Tcell therapy in the scenario of $\mathrm{CD}^{-}{ }^{-}$relapse (Figure 5E) and in silico experiments of changing $F_{\text {NegR }}$ (by scaling $k_{\mathrm{m}}$ and $k_{\mathrm{b}}$ ) again confirmed such observation (Figure 5F). Together, our model help to identify critical determinants underlie heterogeneous responses to CAR T-cell therapy.

\section{In silico prediction of late response at early stage of CAR T-cell treatment}

Prediction of patients' late response to CAR T-cell therapy during early treatment stage will greatly improve patient outcomes by guiding the following regimen, especially for those with acute disease progression (18-20). Having demonstrated that our computational model accurately recapitulated the cellular dynamics of CAR T-cell therapy, we found that the response can be differentiated by the actual function level and dynamics of CAR T-cell in individual patients. Thus, we hypothesized that such responses can be predicted using our computational immuno-oncology model with input of clinically measurable and available patient information related to CAR T-cell dynamics, such as the peak value and AUC7 (area under the curve from day 0 to day 7) of CAR $\mathrm{T}$-cell, at early stage of CAR T-cell treatment.

We first mapped the real-time results of four typical patient groups with different responses (Figure 6A). Unexpectedly, neither of peak value and AUC7 index alone demonstrated statistical differences among different groups, implicating that a single parameter is not proficient for clinical prediction (Supplemental Figure S7). Thus, we considered combining these two indices and defined the prediction factor $F_{\mathrm{P}}$ as

$$
F_{\mathrm{P}}=\log _{2}\left(n_{\text {peak }} \times n_{\mathrm{AUC7}}\right)
$$

where $n_{\text {peak }}$ is the peak value of CAR T-cell and $n_{\mathrm{AUC}}$ is its AUC7 value. For different responses, we calculated $F_{\mathrm{P}}$ based on calibrated results of individual patients, and found that $F_{\mathrm{P}}$ showed statistical significance across CR, NR, and CD19 ${ }^{+}$relapse groups (Figure 6B). The results showed that early-stage CAR T-cell dynamics of CR and CD19- relapse within the first month were similar in terms of the peak value, AUC7 of CAR T-cell and $F_{\mathrm{P}}$, as compared with NR and CD19 ${ }^{+}$relapse. Considering the similarity of CAR T-cell dynamics at early stage between CR and CD19- relapse, these two response groups were combined together in the prediction and defined as CD\&CD19relapse response.

To further validate the prediction ability of $F_{\mathrm{P}}$, for CR\&CD19- relapse, we chose 7 patients for calibrating the relationship between $F_{\mathrm{P}}$ and the response, and 4 (2 CR, 2 CD19- relapse) for prediction; for $\mathrm{NR}$ and $\mathrm{CD} 19^{+}$relapse, we chose 5 for calibration and 2 for prediction. The probability distributions of $F_{\mathrm{P}}$ of different responses are fitted with the MATLAB Distribution Fitter Toolbox (Figure 6C). Based on the probability distribution, the occurrence probabilities of each response at certain $F_{\mathrm{P}}$, i.e., $P_{i}\left(F_{\mathrm{P}}\right)$ can be determined as 


$$
P_{i}\left(F_{\mathrm{P}}\right)=\frac{p_{i}\left(F_{\mathrm{P}}\right)}{\sum_{j=\mathrm{CR} \& \mathrm{CD} 19^{-}, \mathrm{CD} 19^{+}, \mathrm{NR}} p_{j}\left(F_{\mathrm{P}}\right)},\left(i=\mathrm{CR} \& \mathrm{CD} 19^{-}, \mathrm{CD} 19^{+}, \mathrm{NR}\right)
$$

where $p$ is the probability distribution of different responses. We found that as $F_{\mathrm{P}}$ increased, the most likely response of CAR T-cell therapy changed from NR to $\mathrm{CD} 19^{+}$relapse, and then to CR\&CD19- relapse (Figure 6D). $F_{\mathrm{P}}$ of each patient for prediction was calculated and the corresponding probabilities of different responses can be determined (Figure 6D). As a result, $F_{\mathrm{P}}$ of two NR patients are 15.4 and 7.7 and the predicted probabilities of non-response are of $26.7 \%$ and $76.7 \% ; F_{\mathrm{P}}$ of two $\mathrm{CD} 19^{+}$relapse patients are 14.6 and 15.5 and the predicted probabilities of $\mathrm{CD} 19^{+}$relapse are $53.3 \%$ and $55.3 \% ; F_{\mathrm{P}}$ of two $\mathrm{CD} 19^{-}$relapse patients are 18.1 and 19.3 and the predicted probabilities of CR\&CD $19^{-}$relapse are $46.3 \%$ and $68.9 \% ; F_{\mathrm{P}}$ of two $\mathrm{CR}$ patients are 21.9 and 23.2 and the predicted probabilities of CR\&CD19- relapse are $97.2 \%$ and $99.5 \%$.

Given that $F_{\mathrm{P}}$ prediction depended on the peak value of CAR T-cell which requires clinical monitoring of patients up to 2 weeks, we sought to predict patient outcome with only input of the first 7-day clinical data of CAR T-cell dynamics and the initial tumor burden of a given patient. We then calibrated the computational model based on the early-stage CAR T-cell dynamics (Equations 6-8) and obtained the subsequent time-series results of CAR T-cell and tumor cells (Figure 7A-C). To validate the feasibility of the proposed method, we first tested one representative patient for different response group and found that the responses of clinical patient cohort can be correctly predicted (Figure 7A-C).

To test the accuracy of our prediction method on a larger scale with higher reliability, we next generated clinical-derived virtual patient cohorts for a clinical trial simulation to complement the present clinical data which is of small quantity and density (Details see 'Generating virtual patient cohorts' in Methods). In general, 400 virtual patient data points per CR, CD19- relapse, CD19 ${ }^{+}$ relapse and NR cohorts were generated (Supplemental Table S5-8), based on Gaussian distribution of the population level parameters calibrated from present clinical patient cohort data (Table 1). To validate the applicability of those virtual patient cohorts, we first compared the peak value (Figure 7D) and AUC28 (Figure 7E) of CAR T-cells between virtual and clinical patient cohorts of different responses (Figure 5A). The results showed good consistency in both absolute and relative values, indicating the quantity and quality of virtual patient cohorts matched the clinical ones. We further calculated $F_{\mathrm{T}}$ of virtual patient cohorts and found no significant differences between clinical patient cohorts and virtual patient cohorts (Figure 7F), again confirming the usability of virtual patient cohorts. As a result, our clinical trial simulation with virtual patient cohorts successfully reproduced real-time results of corresponding clinical patient cohorts and predicted patient responses (Figure 7G-I, Supplemental Figure S8-11). Overall, our prediction method reached a prediction accuracy of $74.38 \%$ in total of 1,600 virtual patients with respective prediction accuracy of $65.63 \%(525 / 800)$ for CR\&CD19- relapse, $75.50 \%(302 / 400)$ for CD $19^{+}$relapse, and $90.75 \%$ (363/400) for NR (Figure 7J\&K). For CR and CD19- relapse, CAR T-cell dynamics at early stage are similar hence their responses were combined as CR\&CD19relapse (Figure 7A, Supplemental Figure S12). The high prediction accuracy of NR can be partially explained by the lower differences between the predicted and observed values of $F_{\mathrm{T}}, \Delta F_{\mathrm{T}}$ (Supplemental Figure S13).

To further differentiating $\mathrm{CR}$ and $\mathrm{CD} 19^{-}$relapse patients in the group of CR\&CD19- relapse response, we chose the initial CD19- tumor burden as an index to predict the occurrence of CD19relapse (Equation 9). Parameters designated to the model are based on the calibration of CR\&CD19- relapse response combining with parameters related to $\mathrm{CD}^{-} 9^{-}$relapse (Table 1). The 
response varies from $\mathrm{CR}$ to $\mathrm{CD}^{-} 9^{-}$relapse by increasing the initial $\mathrm{CD}^{-} 9^{-}$tumor burden, so its threshold value of each individual and population level results with certain occurrence probabilities to induce CD19- relapse can be determined (Figure 7L, Supplemental Figure S14). These results together confirm the prediction power of our computational CAR T-cell immunooncology model, which can provide guidance for clinical treatment and regimen.

\section{Discussion}

Computational models of immunotherapy provide a valuable tool for in silico clinical modeling and patient stratification $(6,7)$. In the present study, we constructed a mathematical model of the critical leukemia-immune interactions with clinical dataset, determined key factors effecting treatment efficacy, and predicted patient response to CAR T-cell therapy with early-stage CAR Tcell dynamics data. We systematically explored that the dynamic interactions between B-ALL and CAR T-cell and found that CAR T-cell function index $F_{\mathrm{T}}$ inferred patients' outcomes ranging from $\mathrm{CR}, \mathrm{NR}$ to $\mathrm{CD} 19^{+}$relapse. By contrast, a negative relapse index $F_{\text {NegR }}$ including the mutation rate and the bystander killing rate to $\mathrm{CD} 19^{-} \mathrm{B}-\mathrm{ALL}$ cells determined the probability and day of relapse for $\mathrm{CD} 19^{-}$relapse cases. Applying this computational model, we were able to define the prediction factor $F_{\mathrm{P}}$ with the early-stage CAR T-cell dynamics data including the peak and AUC7 values of CAR T-cell to predict CAR T-cell treatment outcomes for individual patients.

Comparing with many other models only end-point data are provided, our model predicted the prognosis of patients with time series data. Many present methods for response prediction required detection of certain prognostic biomarkers, for example inducible COStimulator (ICOS), $\mathrm{CD} 27^{+} \mathrm{PD}-1^{-} \mathrm{CD}^{+} \mathrm{T}$ cell population, lactate dehydrogenase ( $\left.\mathrm{LDH}\right)$, and $\mathrm{C}$-reactive protein (CRP) (21-24), increasing the complexity in practical operation. More importantly, current biomarkers failed to accurately and timely predict the prognosis of patients who underwent CAR T-cell therapy. By contrast, our prediction method needs only inputs of the number of CAR T-cell at early stage of treatment, which is easy to access and commonly measured in clinic, making it acquire higher reliability and potential to be translated into real-world applications.

Computational models usually adopt clinical data from different literatures acquired by different measuring methods (e.g., flow cytometry, qPCR, and morphological testing) of different biopsies took from different tissue samples (e.g., saliva, peripheral blood, and bone marrow). Such a dataset possesses a large variance, making it difficult for model fitting and for obtaining one set of parameters that would work for all patients under different treatment conditions. Thus, unifying the data from different sources and formats before fitting in silico models is particularly important. Accordingly, we built up a unifying code to interpret the relationship between clinical data with different units coming from different body parts with assumptions (12) and data (25). This unifying process of clinical data highlights a novel way to accurately recapitulate the patient/clinical process, which previous strategies are limited to offer. Moreover, the accuracy and reliability of the prognostic model highly depend on the quantity and quality of clinical data to establish and calibrate it. Most critically, limited availability of clinical data prevents large-scale validation of computational models including ours. We therefore conducted clinical trial simulation studies expanding the patient cohorts from 209 to 1,600 individuals. The generation of virtual patient cohorts was based on calibration results of clinical patient cohorts, and the similarity of these two cohorts was carefully confirmed, both ensuring the credibility of clinical trial simulations. The proposed methods to unify and expand clinical data have been proven to be practical and feasible, but it has to be admitted that original clinical data with large amount and uniformed standard are optimal, necessitating collaboration with clinicians on designing the scheme of data collection 
before the start of clinical trials for a better validation and translation of the model. Moreover, the current model tried to fully utilize clinical data obtained from different trials with a uniform and reasonable standard, but it can be improved with more considerations of interpatient variability. For example, lymphodepletion pretreatment seems to effect CAR T-cell expansion (26) and second-generation CAR T-cell products with CD28 or 4-1BB costimulatory domains exhibit differences in magnitude and persistence (27) although both showed well treatment efficacy to BALL. Future extension of the computational model including these factors will develop its potential in exploring new insights.

Relapse scenarios, which were less discussed in current computational models, were included in our model. Our simulation results demonstrated a prediction of the prognosis of CD19 ${ }^{+}$relapse based on early-stage CAR T-cell dynamics data, but not that of $\mathrm{CD}^{-}{ }^{-}$relapse. The clinical responses of $\mathrm{CD}^{-} 9^{-}$relapse patients were found very similar to CR patients at the early stage of CAR T-cell treatment. In our model, the index of initial CD19- tumor burden demonstrated a good potential in predicting CD19- relapse. However, such index of CD19- tumor burden is current less focused and measured clinically, let alone the early-stage measurement (like until day 7) of them, which could provide more sufficient information to calibrate our model for real-world clinical prediction. Although it is clear that presence of $\mathrm{CD}^{-} 9^{-}$tumor cell population caused the CD19relapse (28) and our model identified the potential threshold of the CD19- cell population for CD19- relapse, the mechanisms causing the loss of surface expression of CD19 remain poorly understood. Thus, more insightful studies about the mechanism of CD19- relapse will also enable us to include more factors in the model with improved knowledge to achieve a better description and prediction of $\mathrm{CD}^{-} 9^{-}$relapse.

In addition to the direct interactions between CAR T-cell and B-ALL cell, microenvironmental cues, for example, immune cells like myeloid-derived suppressor cells, regulatory $\mathrm{T}$ cells and tumor-associated macrophages, and their secreted immunosuppressive cytokines in the bone marrow, might explain the distinct functionalities of CAR T-cell for patients with different response (29). As demonstrated by our recent studies (30), an in silico modeling of the heterogeneous tumor microenvironments would be particularly valuable for dissecting and screening of immunotherapies. Incorporation of these immune cell components into our computational immuno-oncology model may help dissecting out these immunological mechanics involved in the tumor microenvironment affecting treatment outcomes, though it remains currently impractical due to highly limited clinical data. Computational models were also applied to study the cytokine release syndrome (CRS), an adverse side effect elicited by CAR T-cell therapy (31, 32). However, most of existing CRS models lack clinical data and failed to dissect actual cellular factors affecting the severity of CRS and corresponding treatments. We believe that modeling of cytokines with our computational CAR T-cell therapy model would help to determine the biological mechanisms and the risk to develop severer CRS and their potential relationships with the varied therapeutic outcomes.

In conclusion, we have established a computational immuno-oncology model of CAR T-cell therapy recapitulating key cellular dynamics observed in clinical trials, revealed key determinants of treatment efficacy, and predicted patient outcomes. We hope that this computational platform inputted with early-stage clinical data can improve the clinical outcomes and guide clinical trials of personalized CAR T-cell therapy.

\section{Materials and Methods Model construction}


CD19+ B-ALL Cell

It is assumed that the proliferation of $\mathrm{CD} 19^{+} \mathrm{B}-\mathrm{ALL}$ cell subjects to logistic growth (33), and they are eliminated by activated CAR T-cell as

$$
\frac{\mathrm{d} n_{\mathrm{P}}}{\mathrm{d} t}=r_{\mathrm{P}}\left(1-\frac{n_{\mathrm{P}}}{n_{\mathrm{C}}}\right) n_{\mathrm{P}}-e \frac{n_{\mathrm{P}}}{n_{\mathrm{P}}+K_{\mathrm{P}}} n_{\mathrm{TA}}
$$

where $n_{\mathrm{P}}$ (P represents positive) is the number of CD19+ $\mathrm{B}-\mathrm{ALL}$ cell, $n_{\mathrm{C}}$ is the carrying capacity of B-ALL cell in the tumor microenvironment, $n_{\mathrm{TA}}$ is the number of activated CAR T-cell, and $e$ is their killing rate. The efficacy of the elimination of B-ALL cell follows Michaelis-Menten kinetics with a Michaelis constant $K_{\mathrm{P}}$, denoting the saturation effect from B-ALL cell to killing efficacy.

\section{CAR T-cell Activation}

CAR T-cell can kill B-ALL cell only after being activated by CD19+ B-ALL cell from initial nonactivated status. The generation of activated CAR T-cell can be expressed as

$$
\frac{\mathrm{d} n_{\mathrm{TA}}}{\mathrm{d} t}=r_{\mathrm{TA}} \frac{n_{\mathrm{P}}}{n_{\mathrm{P}}+K_{r}} n_{\mathrm{TA}}+k_{\mathrm{A}} \frac{n_{\mathrm{P}}}{n_{\mathrm{P}}+K_{\mathrm{A}}} n_{\mathrm{TN}}-l_{\mathrm{TA}} n_{\mathrm{TA}}
$$

where $r_{\mathrm{TA}}$ is the growth rate of activated CAR T-cell, $k_{\mathrm{A}}$ is the activation rate from initial nonactivated CAR T-cell, $n_{\mathrm{TN}}$ is the number of non-activated CAR T-cell, and $l_{\mathrm{TA}}$ is the apoptosis rate of activated CAR T-cell. The growth rate and activation rate of CAR T-cell are affected by CD19 ${ }^{+}$ B-ALL cell with saturation constant $K_{r}$ and $K_{\mathrm{A}}$ respectively.

Thus, the variation of non-activated CAR T-cell can be expressed as

$$
\frac{\mathrm{d} n_{\mathrm{TN}}}{\mathrm{d} t}=-k_{\mathrm{A}} \frac{n_{\mathrm{P}}}{n_{\mathrm{P}}+K_{\mathrm{A}}} n_{\mathrm{TN}}-l_{\mathrm{TN}} n_{\mathrm{TN}}
$$

where the first term represents the conversion to activated status, and $l_{\mathrm{TN}}$ is the apoptosis rate of non-activated CAR T-cell.

\section{$\mathrm{CD}_{19^{+}}$and $\mathrm{CD} 19^{-}$Relapse}

For $\mathrm{CD} 19^{+}$relapse, CD19 antigen is still present on the surface of B-ALL cells and can be detected by flow cytometry, so the model of $\mathrm{CD} 19^{+}$relapse can still be described by equations (6)-(8). However, the response of $\mathrm{CD}_{1} 9^{+}$relapse is different from $\mathrm{CR}$, and the key mechanism lies in the poor function (expansion, cytotoxicity, and persistence) of CAR T-cell (34). For CD19 ${ }^{+}$relapse patients, CAR T-cell parameters in the model such as growth rate, killing rate, activation rate and apoptosis rate should be inferior to CR patients (35).

In CD19- relapse, there exist CD19 antigen absent B-ALL cells, causing tumor to evade CARmediated recognition and clearance in spite of CAR T-cell persistence (4). The mechanism of CD19 loss is attributed to immune pressure selection (CD19-negative tumor cells have already existed before CAR T-cell therapy) and CD19 gene mutation (e.g., alternative slicing with loss of exon 2) (16). In CD19- relapse, although CAR T-cell cannot eliminate CD19- tumor cell through antigen recognition, activated CAR $\mathrm{T}$-cell can mediate tumor lysis against the antigen negative fraction in an antigen independent, cell-cell contact-mediated manner in the vicinity of the cells they're designed to target, which is called bystander killing effect (17). So the variation of CD19tumor cells can be expressed as 


$$
\frac{\mathrm{d} n_{\mathrm{N}}}{\mathrm{d} t}=r_{\mathrm{N}}\left(1-\frac{n_{\mathrm{N}}}{n_{\mathrm{C}}}\right) n_{\mathrm{N}}+k_{\mathrm{m}} n_{\mathrm{P}}-\frac{e}{k_{b}} \frac{n_{\mathrm{N}}}{n_{\mathrm{N}}+K_{\mathrm{N}}} n_{\mathrm{TA}}
$$

where $n_{\mathrm{N}}$ (N represents negative) is the number of $\mathrm{CD}^{-} 9^{-}$tumor cell, $k_{\mathrm{m}}$ is the mutation factor causing CD19 loss from CD19 ${ }^{+}$B-ALL cell, $k_{\mathrm{b}}$ is the bystander killing scaling factor to CD19 ${ }^{+}$ killing efficacy, and $K_{\mathrm{N}}$ is the saturation constant depicting the effect of CD19- B-ALL cells to bystander killing.

\section{Collecting and processing clinical data}

Merging the individual data into groups

Real-time data of CAR T-cell and tumor burden including the information of 209 patients were collected from clinical studies $(25,35-43)$. For clinical trials that did not disclose raw data, the clinical data were digitized by WebPlotDigitizer (https://automeris.io/WebPlotDigitizer) from published figures of these clinical studies.

Although in some studies there are clinical data of individual patients, for some studies, individual data had been preprocessed and we can only get the statistical values like medians from such references. However, it does not weaken the reliability of the calibration process and the rationality of the computational model, since such statistical values still contain the information of individual patient. Thus, for one piece of available clinical data (containing one or several individuals), we called it a group. After summarizing the data in references, we got 32 groups (14 for $\mathrm{CR}, 7$ for NR, 7 for $\mathrm{CD} 19^{+}$relapse, and 4 for $\mathrm{CD}^{-} 9^{-}$relapse) including the clinical information of 209 individuals (148 for CR groups, 24 for NR groups, 20 for CD19 ${ }^{+}$relapse groups, and 17 for CD19` relapse groups) (Supplemental Table 1-4).

\section{Converting data from peripheral blood to bone marrow}

The computational model dissects the cellular behaviors in the B-ALL bone marrow during CAR T-cell therapy. However, samples are often collected in peripheral blood clinically (e.g., CAR Tcell). So, such data need to be converted into their equivalent values in bone marrow. For data acquired in peripheral blood, it is assumed that the average volume of blood sample is $5 \mathrm{~mL}$ and there are $5000 \mathrm{~mL}$ bloods in human body (44). So the number of cells in the whole peripheral blood can be calculated. After that, it is assumed that comparing with bone marrow, about $1 \%$ cells are in peripheral blood (12). Thus, the number of cells in bone marrow can be obtained.

\section{Unifying the units of $B$-ALL cells}

In most clinical studies, the unit of B-ALL cells is tumor burden (\%). However, the proposed CAR T-cell therapy model is cellular-based, so for computational processes like calibration and simulation, the unit of B-ALL cells need to be converted into number of B-ALL cells. We got the clinical pre-treatment tumor burdens (Table 1 of ref. (25)) and absolute numbers of B-ALL cells (Figure 1G of ref.(25)) of $\mathrm{MRD}^{-}$patients, and their relationship was determined after fitting (Supplement Figure S15). The expression of the fitted results is

$$
\text { B-ALL cell number }\left(\times 10^{9} \text { cells }\right)=1909 \times \frac{\text { Tumor burden }(\%)}{97.19-\text { Tumor burden }(\%)}
$$

It is noted that although the unit of B-ALL cells were converted into absolute numbers for computation, the unit was converted back into tumor burden (\%) for presentation in our paper to make it more understandable and compliant with clinical custom. 
Unifying the units and scaling of CAR T-cells

Like B-ALL cells, the units of CAR T-cell were all converted into number of CAR T-cells $\left(\times 10^{9}\right)$ for computation. Clinically the amount of CAR T-cell are often measured by quantitative PCR (qPCR) (normally in the unit of copies CAR/ $\mu \mathrm{g}$ DNA) in peripheral blood. From Figure 1F of ref. (25), we obtained the qPCR values and corresponding absolute numbers of CAR T-cell of MRDpatients. Considering the samples of these two measurement methods were of different numbers ( $\mathrm{n}=14$ for $\mathrm{qPCR}$ values and $\mathrm{n}=11$ for absolute numbers) in (25), we got the median of these two values and determined their relationship as

$$
\text { CAR-T cell number }\left(\times 10^{9} \text { cells }\right)=0.10205 \times \mathrm{qPCR} \text { values }(\text { copies } / \mu \mathrm{g} \mathrm{DNA})
$$

Comparing to CR patients and NR patients, clinical data of CAR T-cell of CD19 ${ }^{+}$and CD19relapse is relatively lack in clinical studies, thus requiring more process.

According to current clinical researches, $\mathrm{CD} 19^{+}$relapse is associated with loss of CAR T-cell function. In contrast, CD19- relapse occurs despite CAR T-cell functional persistence and they are likely to be independent of CAR T-cell parameters per se (34). For $\mathrm{CD}_{1} 9^{+}$relapse patients, the function of CAR T-cell is between CR and NR patients; and for CD19- relapse patients, the function of CAR T-cell is similar to CR patients (35). So it is reasonably assumed that the values of CAR T-cell of CD19 $9^{+}$relapse patients is between CR and NR patients, of CD19- relapse patients is close to CR patients. In this paper, based on the above assumption, we scaled the limited amount of data of CAR T-cell for CD19+ and CD19- relapse. With the support of biological and clinical studies, the reliability of the computational model is maintained although with scaling, especially for comparisons and analysis inside $\mathrm{CD} 19^{+}$or $\mathrm{CD} 19^{-}$relapse patient groups.

\section{Parameter estimation}

Parameter estimation (on individual and population level) were conducted using the stochastic approximation expectation maximization (SAEM) algorithm for nonlinear mixed-effect modeling (NLME), as implemented in Monolix version 2020R1 (Lixoft, France). The estimated population level-parameters and initial values related to CAR T-cells and tumor cells (Table 1) were obtained. References in Table 1 determined the rational ranges of estimated parameters.

\section{Generating virtual patient cohorts}

The parameters of virtual patient cohorts were generated obeying the Gaussian distribution with mean value $\mu$ equaling to the population leveled-parameters (Table 1) of CR, CD19 ${ }^{+}$relapse and NR patients. The standard deviation equals to $1 / 3 \mu$ ensuring the parameters are larger than 0 . For each population leveled-parameters of each response, we generated 400 sets of parameters of continuous remission, $\mathrm{CD} 19^{-}$relapse, $\mathrm{CD} 19^{+}$relapse and non-response respectively.

\section{Statistics}

Data were first analyzed for normality and then compared with unpaired Student's $t$ test or Welch's $\mathrm{t}$ test using Prism 7.0 (GraphPad). $* \mathrm{p}<0.05, * * \mathrm{p}<0.01$, and $* * * \mathrm{p}<0.001$ were considered significantly different. The results, including the error bars in the graphs, were given as the mean \pm standard error of mean (SEM) or boxplot with whisker of min to max value. Details are reported in each figure.

\section{Acknowledgements}

Funding: This work was supported by the National Science Foundation (CBET 2103219), the US National Institutes of Health (R35GM133646). C.M. is the recipient of a Cancer Research Institute 
medRxiv preprint doi: https://doi.org/10.1101/2021.09.21.21263913; this version posted September 23, 2021. The copyright holder for this preprint (which was not certified by peer review) is the author/funder, who has granted medRxiv a license to display the preprint in perpetuity.

It is made available under a CC-BY-NC-ND 4.0 International license .

Irvington Postdoctoral Fellowship (CRI4018). Author contributions: C.M. and W.C. conceived the project; L.L. and Z.Z. constructed the computational model and performed experiments; L.L., Z.Z., and C.M. analyzed data; L.L., Z. Z., C.M. and W.C. wrote the manuscript; W.C. supervised the project. All authors edited and approved the final manuscript. Competing interests: The authors declare no competing financial interest. Data availability: All the relevant data are included in the manuscript and its supplementary material file. The code for the computational model is available on Github (https://github.com/Lunan12/CAR-T-model). 


\section{References and Notes}

1. V. Prasad, Immunotherapy: Tisagenlecleucel - the first approved CAR-T-cell therapy: implications for payers and policy makers. Nat Rev Clin Oncol 15, 11-12 (2018).

2. N. Bouchkouj, Y. L. Kasamon, R. A. de Claro, B. George, X. Lin, S. Lee, G. M. Blumenthal, W. Bryan, A. E. McKee, R. Pazdur, FDA Approval Summary: Axicabtagene Ciloleucel for Relapsed or Refractory Large B-cell Lymphoma. Clin Cancer Res 25, 17021708 (2019).

3. S. Lesch, M. R. Benmebarek, B. L. Cadilha, S. Stoiber, M. Subklewe, S. Endres, S. Kobold, Determinants of response and resistance to CAR T cell therapy. Semin Cancer Biol 65, 8090 (2020).

4. X. Xu, Q. Sun, X. Liang, Z. Chen, X. Zhang, X. Zhou, M. Li, H. Tu, Y. Liu, S. Tu, Y. Li, Mechanisms of Relapse After CD19 CAR T-Cell Therapy for Acute Lymphoblastic Leukemia and Its Prevention and Treatment Strategies. Front Immunol 10, 2664 (2019).

5. J. Cheng, L. Zhao, Y. Zhang, Y. Qin, Y. Guan, T. Zhang, C. Liu, J. Zhou, Understanding the Mechanisms of Resistance to CAR T-Cell Therapy in Malignancies. Front Oncol 9, 1237 (2019).

6. D. Valentinuzzi, R. Jeraj, Computational modelling of modern cancer immunotherapy. Phys Med Biol 65, 24TR01 (2020).

7. Z. Agur, K. Halevi-Tobias, Y. Kogan, O. Shlagman, Employing dynamical computational models for personalizing cancer immunotherapy. Expert Opinion on Biological Therapy 16, 1373-1385 (2016).

8. A. P. Singh, X. Zheng, X. Lin-Schmidt, W. Chen, T. J. Carpenter, A. Zong, W. Wang, D. L. Heald, Development of a quantitative relationship between CAR-affinity, antigen abundance, tumor cell depletion and CAR-T cell expansion using a multiscale systems PKPD model. MAbs 12, 1688616 (2020).

9. A. M. Stein, S. A. Grupp, J. E. Levine, T. W. Laetsch, M. A. Pulsipher, M. W. Boyer, K. J. August, B. L. Levine, L. Tomassian, S. Shah, M. Leung, P. H. Huang, R. Awasthi, K. T. Mueller, P. A. Wood, C. H. June, Tisagenlecleucel Model-Based Cellular Kinetic Analysis of Chimeric Antigen Receptor-T Cells. CPT Pharmacometrics Syst Pharmacol 8, 285-295 (2019).

10. P. Sahoo, X. Yang, D. Abler, D. Maestrini, V. Adhikarla, D. Frankhouser, H. Cho, V. Machuca, D. Wang, M. Barish, M. Gutova, S. Branciamore, C. E. Brown, R. C. Rockne, Mathematical deconvolution of CAR T-cell proliferation and exhaustion from real-time killing assay data. J R Soc Interface 17, 20190734 (2020).

11. C. G. Cess, S. D. Finley, Data-driven analysis of a mechanistic model of CAR T cell signaling predicts effects of cell-to-cell heterogeneity. J Theor Biol 489, 110125 (2020).

12. G. J. Kimmel, F. L. Locke, P. M. Altrock, The roles of T cell competition and stochastic extinction events in chimeric antigen receptor T cell therapy. Proc Biol Sci 288, 20210229 (2021).

13. C. Liu, V. S. Ayyar, X. Zheng, W. Chen, S. Zheng, H. Mody, W. Wang, D. Heald, A. P. Singh, Y. Cao, Model-Based Cellular Kinetic Analysis of Chimeric Antigen Receptor-T Cells in Humans. Clin Pharmacol Ther 109, 716-727 (2021).

14. N. H. G. Holford, H. C. Kimko, J. P. R. Monteleone, C. C. Peck, Simulation of Clinical Trials. Annual Review of Pharmacology and Toxicology 40, 209-234 (2000).

15. N. Holford, S. C. Ma, B. A. Ploeger, Clinical Trial Simulation: A Review. Clinical Pharmacology \& Therapeutics 88, 166-182 (2010). 
16. M. Ruella, M. V. Maus, Catch me if you can: Leukemia Escape after CD19-Directed T Cell Immunotherapies. Comput Struct Biotechnol J 14, 357-362 (2016).

17. M. R. Benmebarek, C. H. Karches, B. L. Cadilha, S. Lesch, S. Endres, S. Kobold, Killing Mechanisms of Chimeric Antigen Receptor (CAR) T Cells. Int J Mol Sci 20, (2019).

18. X. Zhang, J. Yang, W. Li, G. Zhang, Y. Su, Y. Shi, D. Song, M. Zhang, J. He, L. Xu, J. Li, X. Lu, J. Li, X. Li, Z. Xu, Z. Li, P. Lu, Factors Predicting Long-Term Survival Following CD19 CAR T-Cell Therapy in Relapsed/Refractory B-Cell Acute Lymphoblastic Leukemia. Blood 136, 1-2 (2020).

19. L. Vercellino, R. Di Blasi, S. Kanoun, B. Tessoulin, C. Rossi, M. D'Aveni-Piney, L. Obéric, C. Bodet-Milin, P. Bories, P. Olivier, I. Lafon, A. Berriolo-Riedinger, E. Galli, S. Bernard, M.-T. Rubio, C. Bossard, V. Meignin, P. Merlet, P. Feugier, S. Le Gouill, L. Ysebaert, O. Casasnovas, M. Meignan, S. Chevret, C. Thieblemont, Predictive factors of early progression after CAR T-cell therapy in relapsed/refractory diffuse large B-cell lymphoma. Blood Advances 4, 5607-5615 (2020).

20. A. Mueller-Schoell, N. Puebla-Osorio, R. Michelet, M. R. Green, A. Kunkele, W. Huisinga, P. Strati, B. Chasen, S. S. Neelapu, C. Yee, C. Kloft, Early Survival Prediction Framework in CD19-Specific CAR-T Cell Immunotherapy Using a Quantitative Systems Pharmacology Model. Cancers (Basel) 13, (2021).

21. A. Volpe, V. L. Nagle, J. S. Lewis, V. Ponomarev, Predicting CAR-T cell immunotherapy success through immunoPET. Clinical Cancer Research, clincanres.4297.2020 (2020).

22. J. A. Fraietta, S. F. Lacey, E. J. Orlando, I. Pruteanu-Malinici, M. Gohil, S. Lundh, A. C. Boesteanu, Y. Wang, R. S. O’Connor, W.-T. Hwang, E. Pequignot, D. E. Ambrose, C. Zhang, N. Wilcox, F. Bedoya, C. Dorfmeier, F. Chen, L. Tian, H. Parakandi, M. Gupta, R. M. Young, F. B. Johnson, I. Kulikovskaya, L. Liu, J. Xu, S. H. Kassim, M. M. Davis, B. L. Levine, N. V. Frey, D. L. Siegel, A. C. Huang, E. J. Wherry, H. Bitter, J. L. Brogdon, D. L. Porter, C. H. June, J. J. Melenhorst, Determinants of response and resistance to CD19 chimeric antigen receptor (CAR) T cell therapy of chronic lymphocytic leukemia. Nature Medicine 24, 563-571 (2018).

23. R. Hong, Y. Hu, H. Huang, Biomarkers for Chimeric Antigen Receptor T Cell Therapy in Acute Lymphoblastic Leukemia: Prospects for Personalized Management and Prognostic Prediction. Frontiers in Immunology 12, (2021).

24. L. Vercellino, R. Di Blasi, S. Kanoun, B. Tessoulin, C. Rossi, M. D'Aveni-Piney, L. Obéric, C. Bodet-Milin, P. Bories, P. Olivier, I. Lafon, A. Berriolo-Riedinger, E. Galli, S. Bernard, M. T. Rubio, C. Bossard, V. Meignin, P. Merlet, P. Feugier, S. Le Gouill, L. Ysebaert, O. Casasnovas, M. Meignan, S. Chevret, C. Thieblemont, Predictive factors of early progression after CAR T-cell therapy in relapsed/refractory diffuse large B-cell lymphoma. Blood Adv 4, 5607-5615 (2020).

25. D. W. Lee, J. N. Kochenderfer, M. Stetler-Stevenson, Y. K. Cui, C. Delbrook, S. A. Feldman, T. J. Fry, R. Orentas, M. Sabatino, N. N. Shah, S. M. Steinberg, D. Stroncek, N. Tschernia, C. Yuan, H. Zhang, L. Zhang, S. A. Rosenberg, A. S. Wayne, C. L. Mackall, T cells expressing CD19 chimeric antigen receptors for acute lymphoblastic leukaemia in children and young adults: a phase 1 dose-escalation trial. The Lancet 385, 517-528 (2015).

26. N. N. Shah, T. J. Fry, Mechanisms of resistance to CAR T cell therapy. Nat Rev Clin Oncol 16, 372-385 (2019).

27. A. I. Salter, R. G. Ivey, J. J. Kennedy, V. Voillet, A. Rajan, E. J. Alderman, U. J. Voytovich, C. Lin, D. Sommermeyer, L. Liu, J. R. Whiteaker, R. Gottardo, A. G. Paulovich, S. R. 
Riddell, Phosphoproteomic analysis of chimeric antigen receptor signaling reveals kinetic and quantitative differences that affect cell function. Sci Signal 11, (2018).

28. P. Domizi, A. Jager, J. Sarno, C. G. Mullighan, S. Grupp, E. Sotillo, D. M. Barrett, K. L. Davis, Prediction of Patients at Risk of CD19Neg Relapse Following CD19-Directed CAR T Cell Therapy in B Cell Precursor Acute Lymphoblastic Leukemia. Blood 134, 749-749 (2019).

29. M. T. Witkowski, I. Dolgalev, N. A. Evensen, C. Ma, T. Chambers, K. G. Roberts, S. Sreeram, Y. Dai, A. N. Tikhonova, A. Lasry, C. Qu, D. Pei, C. Cheng, G. A. Robbins, J. Pierro, S. Selvaraj, V. Mezzano, M. Daves, P. J. Lupo, M. E. Scheurer, C. A. Loomis, C. G. Mullighan, W. Chen, K. R. Rabin, A. Tsirigos, W. L. Carroll, I. Aifantis, Extensive Remodeling of the Immune Microenvironment in B Cell Acute Lymphoblastic Leukemia. Cancer Cell 37, 867-882.e812 (2020).

30. Z. Zhang, L. Liu, C. Ma, X. Cui, R. H. W. Lam, W. Chen, An In Silico Glioblastoma Microenvironment Model Dissects the Immunological Mechanisms of Resistance to PD-1 Checkpoint Blockade Immunotherapy. Small Methods 5, 2100197 (2021).

31. D. Hardiansyah, C. M. Ng, Quantitative Systems Pharmacology Model of Chimeric Antigen Receptor T-Cell Therapy. Clin Transl Sci 12, 343-349 (2019).

32. H. H. Yiu, A. L. Graham, R. F. Stengel, Dynamics of a cytokine storm. PLoS One 7, e45027 (2012).

33. H. Murphy, H. Jaafari, H. M. Dobrovolny, Differences in predictions of ODE models of tumor growth: a cautionary example. BMC Cancer 16, 163 (2016).

34. V. Pillai, K. Muralidharan, W. Meng, A. Bagashev, D. A. Oldridge, J. Rosenthal, J. Van Arnam, J. J. Melenhorst, D. Mohan, A. M. DiNofia, M. Luo, S. Cherian, J. R. Fromm, G. Wertheim, A. Thomas-Tikhonenko, M. Paessler, C. H. June, E. T. Luning Prak, V. G. Bhoj, S. A. Grupp, S. L. Maude, S. R. Rheingold, CAR T-cell therapy is effective for CD19-dim B-lymphoblastic leukemia but is impacted by prior blinatumomab therapy. Blood Adv 3, 3539-3549 (2019).

35. K. A. Hay, J. Gauthier, A. V. Hirayama, J. M. Voutsinas, Q. Wu, D. Li, T. A. Gooley, S. Cherian, X. Chen, B. S. Pender, R. M. Hawkins, A. Vakil, R. N. Steinmetz, G. Schoch, A. G. Chapuis, B. G. Till, H.-P. Kiem, J. D. Ramos, M. Shadman, R. D. Cassaday, U. H. Acharya, S. R. Riddell, D. G. Maloney, C. J. Turtle, Factors associated with durable EFS in adult B-cell ALL patients achieving MRD-negative CR after CD19 CAR T-cell therapy. Blood 133, 1652-1663 (2019).

36. S. L. Maude, T. W. Laetsch, J. Buechner, S. Rives, M. Boyer, H. Bittencourt, P. Bader, M. R. Verneris, H. E. Stefanski, G. D. Myers, M. Qayed, B. De Moerloose, H. Hiramatsu, K. Schlis, K. L. Davis, P. L. Martin, E. R. Nemecek, G. A. Yanik, C. Peters, A. Baruchel, N. Boissel, F. Mechinaud, A. Balduzzi, J. Krueger, C. H. June, B. L. Levine, P. Wood, T. Taran, M. Leung, K. T. Mueller, Y. Zhang, K. Sen, D. Lebwohl, M. A. Pulsipher, S. A. Grupp, Tisagenlecleucel in Children and Young Adults with B-Cell Lymphoblastic Leukemia. N Engl J Med 378, 439-448 (2018).

37. S. A. Grupp, M. Kalos, D. Barrett, R. Aplenc, D. L. Porter, S. R. Rheingold, D. T. Teachey, A. Chew, B. Hauck, J. F. Wright, M. C. Milone, B. L. Levine, C. H. June, Chimeric antigen receptor-modified T cells for acute lymphoid leukemia. $N$ Engl J Med 368, 1509-1518 (2013).

38. C. J. Turtle, L. A. Hanafi, C. Berger, T. A. Gooley, S. Cherian, M. Hudecek, D. Sommermeyer, K. Melville, B. Pender, T. M. Budiarto, E. Robinson, N. N. Steevens, C. 
Chaney, L. Soma, X. Chen, C. Yeung, B. Wood, D. Li, J. Cao, S. Heimfeld, M. C. Jensen, S. R. Riddell, D. G. Maloney, CD19 CAR-T cells of defined CD4+:CD8+ composition in adult B cell ALL patients. J Clin Invest 126, 2123-2138 (2016).

39. R. J. Brentjens, M. L. Davila, I. Riviere, J. Park, X. Wang, L. G. Cowell, S. Bartido, J. Stefanski, C. Taylor, M. Olszewska, O. Borquez-Ojeda, J. Qu, T. Wasielewska, Q. He, Y. Bernal, I. V. Rijo, C. Hedvat, R. Kobos, K. Curran, P. Steinherz, J. Jurcic, T. Rosenblat, P. Maslak, M. Frattini, M. Sadelain, CD19-Targeted T Cells Rapidly Induce Molecular Remissions in Adults with Chemotherapy-Refractory Acute Lymphoblastic Leukemia. Science Translational Medicine 5, 177ra138-177ra138 (2013).

40. R. A. Gardner, O. Finney, C. Annesley, H. Brakke, C. Summers, K. Leger, M. Bleakley, C. Brown, S. Mgebroff, K. S. Kelly-Spratt, V. Hoglund, C. Lindgren, A. P. Oron, D. Li, S. R. Riddell, J. R. Park, M. C. Jensen, Intent-to-treat leukemia remission by CD19 CAR T cells of defined formulation and dose in children and young adults. Blood 129, 3322-3331 (2017).

41. M. L. Davila, I. Riviere, X. Wang, S. Bartido, J. Park, K. Curran, S. S. Chung, J. Stefanski, O. Borquez-Ojeda, M. Olszewska, J. Qu, T. Wasielewska, Q. He, M. Fink, H. Shinglot, M. Youssif, M. Satter, Y. Wang, J. Hosey, H. Quintanilla, E. Halton, Y. Bernal, D. C. G. Bouhassira, M. E. Arcila, M. Gonen, G. J. Roboz, P. Maslak, D. Douer, M. G. Frattini, S. Giralt, M. Sadelain, R. Brentjens, Efficacy and Toxicity Management of 19-28z CAR T Cell Therapy in B Cell Acute Lymphoblastic Leukemia. Science Translational Medicine 6, 224ra225-224ra225 (2014).

42. S. Li, J. Zhang, M. Wang, G. Fu, Y. Li, L. Pei, Z. Xiong, D. Qin, R. Zhang, X. Tian, Z. Wei, R. Chen, X. Chen, J. Wan, J. Chen, X. Wei, Y. Xu, P. Zhang, P. Wang, X. Peng, S. Yang, J. Shen, Z. Yang, J. Chen, C. Qian, Treatment of acute lymphoblastic leukaemia with the second generation of CD19 CAR-T containing either CD28 or 4-1BB. $\mathrm{Br} J$ Haematol 181, 360-371 (2018).

43. R. Gardner, D. Wu, S. Cherian, M. Fang, L. A. Hanafi, O. Finney, H. Smithers, M. C. Jensen, S. R. Riddell, D. G. Maloney, C. J. Turtle, Acquisition of a CD19-negative myeloid phenotype allows immune escape of MLL-rearranged B-ALL from CD19 CAR-T-cell therapy. Blood 127, 2406-2410 (2016).

44. T. A. Manzone, H. Q. Dam, D. Soltis, V. V. Sagar, Blood volume analysis: a new technique and new clinical interest reinvigorate a classic study. J Nucl Med Technol 35, 55-63; quiz 77, 79 (2007).

45. A. Hirt, E. M. Werren, A. R. Luethy, J. Gerdes, H. P. Wagner, Cell cycle analysis in lymphoid neoplasia of childhood: differences among immunologic subtypes and similarities in the proliferation of normal and leukaemic precursor B cells. Br J Haematol 80, 189-193 (1992).

46. J. Cooperman, R. Neely, D. T. Teachey, S. Grupp, J. K. Choi, Cell division rates of primary human precursor B cells in culture reflect in vivo rates. Stem Cells 22, 1111-1120 (2004).

47. X. Zhao, J. Yang, X. Zhang, X. A. Lu, M. Xiong, J. Zhang, X. Zhou, F. Qi, T. He, Y. Ding, X. Hu, F. De Smet, P. Lu, X. Huang, Efficacy and Safety of CD28- or 4-1BB-Based CD19 CAR-T Cells in B Cell Acute Lymphoblastic Leukemia. Mol Ther Oncolytics 18, 272-281 (2020).

48. D. C. Macallan, B. Asquith, A. J. Irvine, D. L. Wallace, A. Worth, H. Ghattas, Y. Zhang, G. E. Griffin, D. F. Tough, P. C. Beverley, Measurement and modeling of human T cell kinetics. Eur J Immunol 33, 2316-2326 (2003). 
medRxiv preprint doi: https://doi.org/10.1101/2021.09.21.21263913; this version posted September 23, 2021. The copyright holder for this preprint (which was not certified by peer review) is the author/funder, who has granted medRxiv a license to display the preprint in perpetuity.

It is made available under a CC-BY-NC-ND 4.0 International license .

49. R. M. Ribeiro, H. Mohri, D. D. Ho, A. S. Perelson, In vivo dynamics of T cell activation, proliferation, and death in HIV-1 infection: why are CD4+ but not CD8+ T cells depleted? Proc Natl Acad Sci U S A 99, 15572-15577 (2002).

50. J. C. Roach, G. Glusman, A. F. A. Smit, C. D. Huff, R. Hubley, P. T. Shannon, L. Rowen, K. P. Pant, N. Goodman, M. Bamshad, J. Shendure, R. Drmanac, L. B. Jorde, L. Hood, D. J. Galas, Analysis of Genetic Inheritance in a Family Quartet by Whole-Genome Sequencing. Science 328, 636 (2010). 
medRxiv preprint doi: https://doi.org/10.1101/2021.09.21.21263913; this version posted September 23, 2021. The copyright holder for this preprint (which was not certified by peer review) is the author/funder, who has granted medRxiv a license to display the preprint in perpetuity.

\section{Figures and Legends}
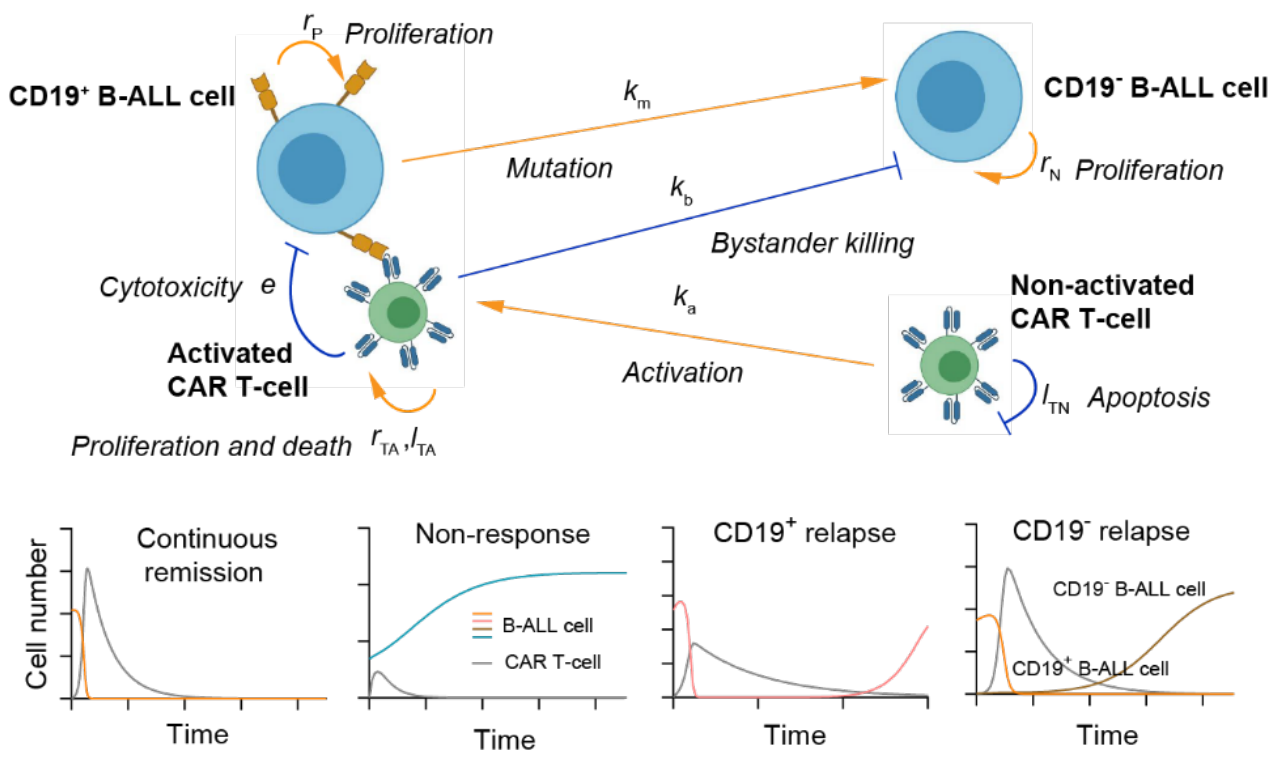

Figure 1. A schematic showing the key cellular components and their dynamic interactions in the computational CAR T-cell therapy model. Based on the computational model, four kinds of responses (bottom panel): continuous remission, non-response, $\mathrm{CD} 19^{+}$relapse and $\mathrm{CD}^{-}{ }^{-}$ relapse can be recapitulated with the outputs of dynamics of CAR T-cell and B-ALL cell. 

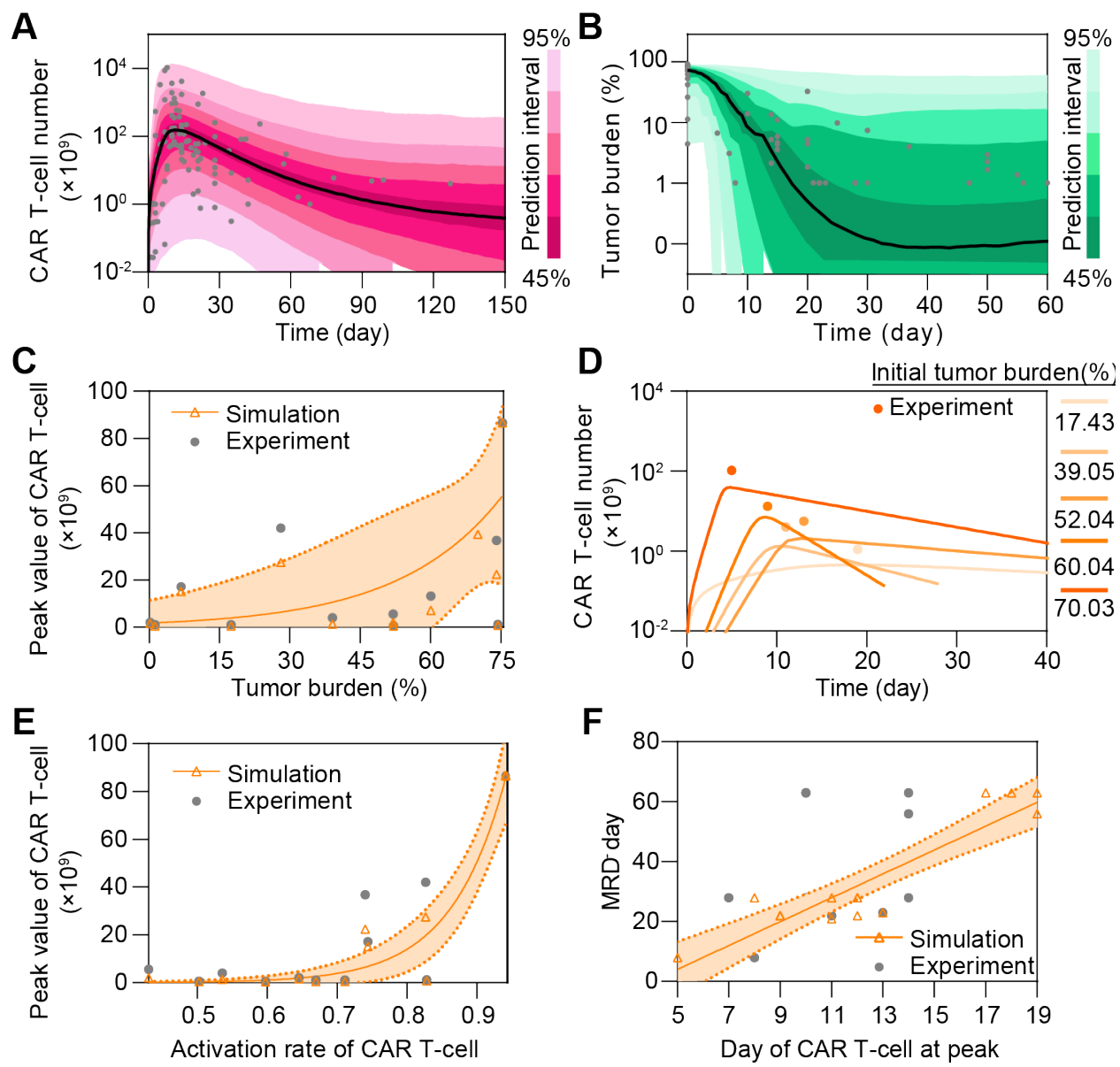

Figure 2. In silico analysis of continuous remission to CAR T-cell therapy. (A\&B) Calibration results of CAR T-cell (A) and tumor burden (B) of remission patients with median (solid line) and 95\% prediction interval (color bands). The dots represent the experimental data. Prediction interval was automatically generated by the predefined algorithm of Monolix software during calibration. (C) Relationship between tumor burden and peak value of CAR T-cell and (D) corresponding realtime results. Simulation results of different patient groups were calculated and fitted with dashed lines, and compared with experimental results in $\mathrm{D}$. The band in $\mathrm{C}$ represents the $95 \%$ confidence interval (the same below). (E\&F) Relationships between the activation rate and peak value of CAR T-cell (E), and day of CAR T-cell at peak and MRD' day $(\mathbf{F})$. 

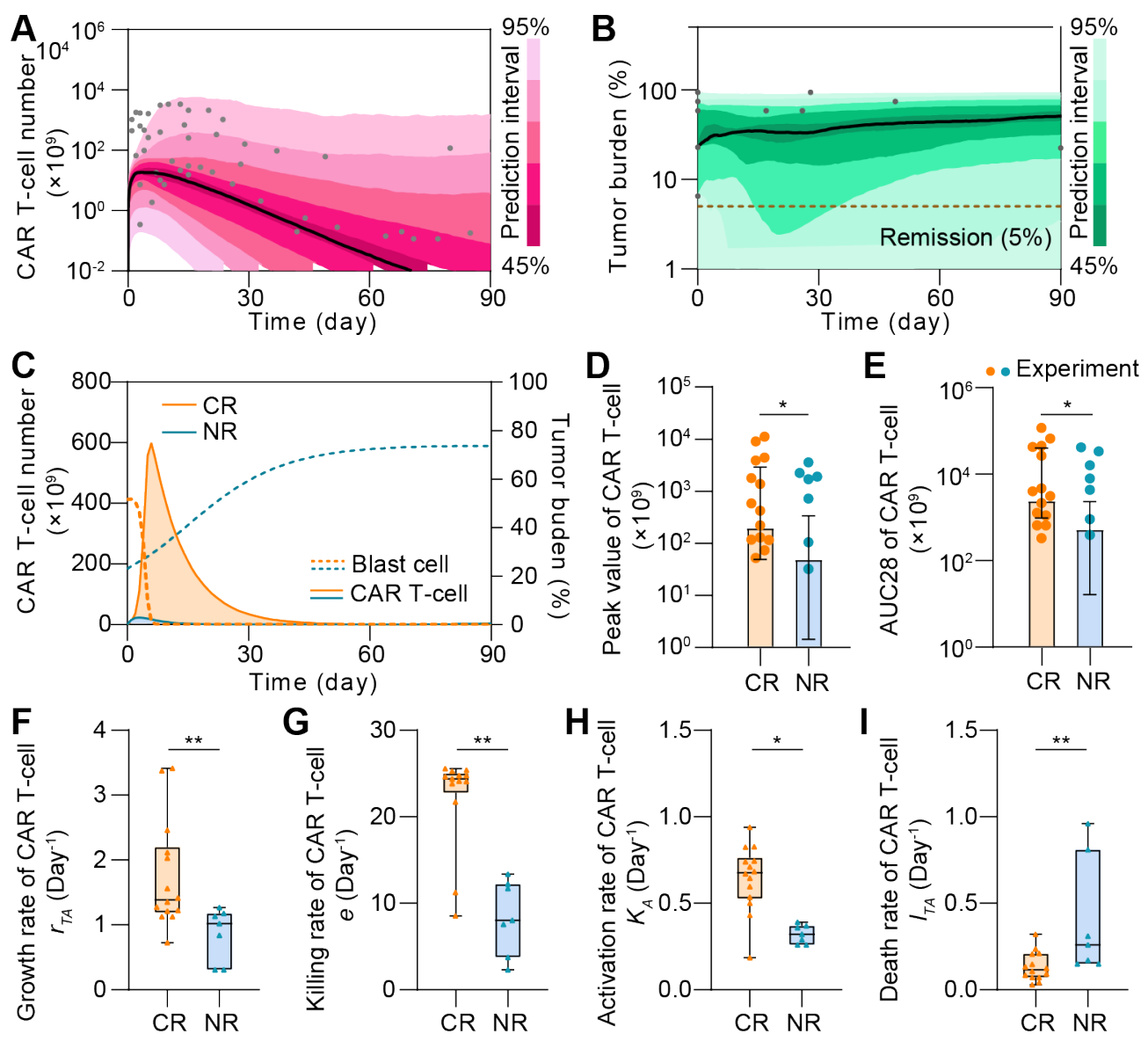

Figure 3. Comparative analysis of CR and NR patients in silico. (A\&B) Calibration results of CAR T-cell (A) and tumor burdens (B) of NR patients with median (solid line) and $95 \%$ prediction interval (color bands). The dots represent the experimental data. (C) Variations of CAR T-cell and tumor burden of CR and NR patients. (D\&E) Comparisons of the peak value (D) and AUC28 of CAR T-cell (E) between CR and NR patients. Bars are simulated results and dots are experiment results. Error bars are mean with $95 \%$ confidence interval. (F-I) The median growth rate of CAR T-cells of CR patients is 1.38 day $^{-1}$, comparing with 1.02 day $^{-1}$ of NR $(\mathbf{F})$, the killing rate is 24.25 day $^{-1}$ vs. 8.03 day $^{-1}(\mathbf{G})$, the activation rate is 0.70 day $^{-1}$ vs. 0.32 day $^{-1}(\mathbf{H})$, and the apoptosis rate is 0.12 day $^{-1}$ vs. 0.26 day $^{-1}(\mathbf{I})$. Whiskers of boxplots are min to max value. $P$-values were calculated using Student's or Welch's t-test. ${ }^{*} \mathrm{p}<0.05,{ }^{* *} \mathrm{p}<0.01$. 
medRxiv preprint doi: https://doi.org/10.1101/2021.09.21.21263913; this version posted September 23, 2021. The copyright holder for this preprint (which was not certified by peer review) is the author/funder, who has granted medRxiv a license to display the preprint in perpetuity.

It is made available under a CC-BY-NC-ND 4.0 International license .

CD19+ relapse

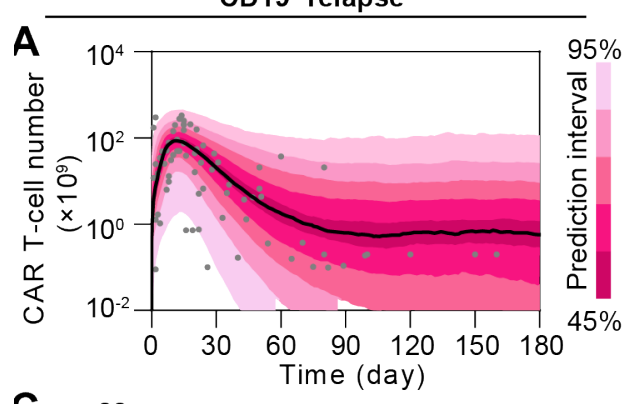

C

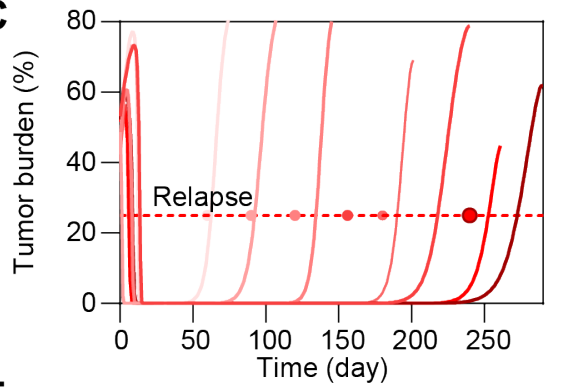

E
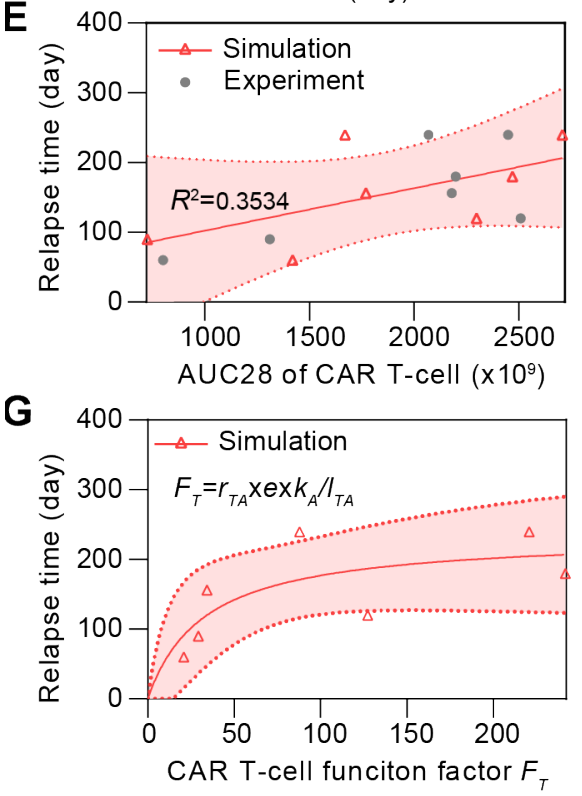

CD19- relapse
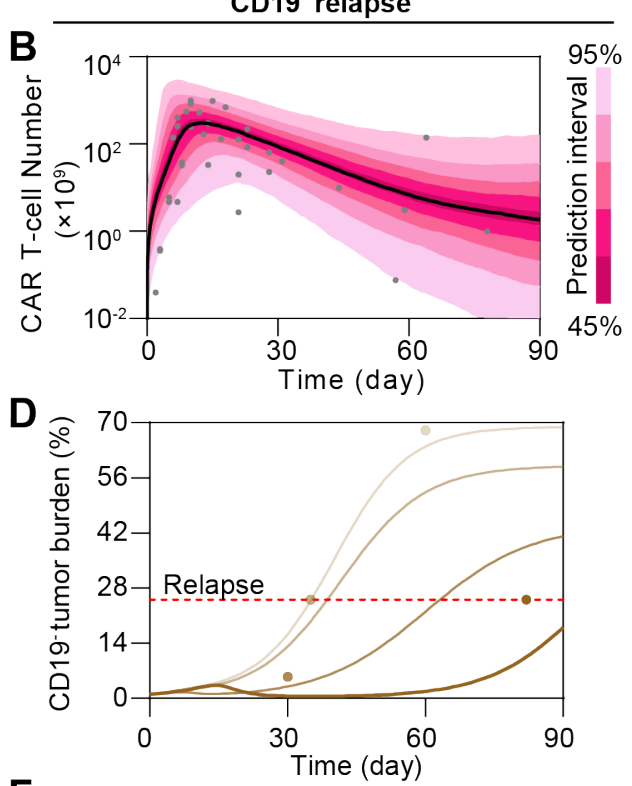

$\mathbf{F}$
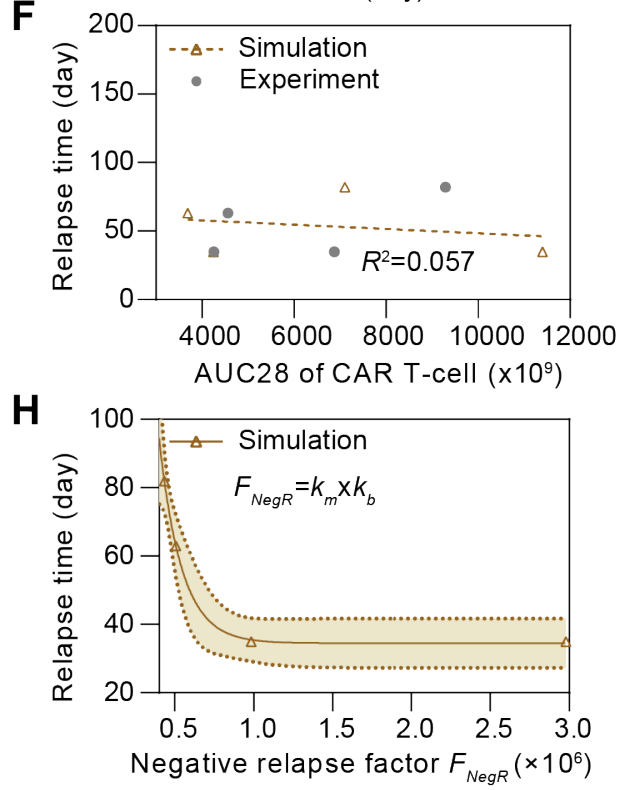

Figure 4. Comparative analysis of $\mathrm{CD}^{+}{ }^{+}$and $\mathrm{CD}^{-}{ }^{-}$relapse to $\mathrm{CAR}$ T-cell therapy in silico. $(\mathbf{A \& B})$ Calibration results of CAR T-cell of $\mathrm{CD}_{19}{ }^{+}(\mathbf{A})$ and $\mathrm{CD}^{-} 9^{-}(\mathbf{B})$ relapse with median (solid line) and 95\% prediction interval (color bands). (C\&D) Individual fitting results of tumor burden of $\mathrm{CD}_{19}{ }^{+}$(C) and CD19- relapse (D). In A-D, the dots represent the experimental data and the lines represent the fitted curves. (E\&F) Relationships between AUC28 of CAR T-cell and day of

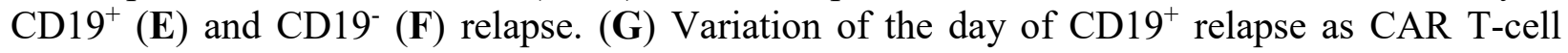
function factor $F_{\mathrm{T}}$ changes. $(\mathbf{H})$ Variation of the day of $\mathrm{CD} 19^{-}$relapse as negative relapse factor $F_{\text {NegR }}$ changes. The band in E, G, H represents the $95 \%$ confidence interval. 

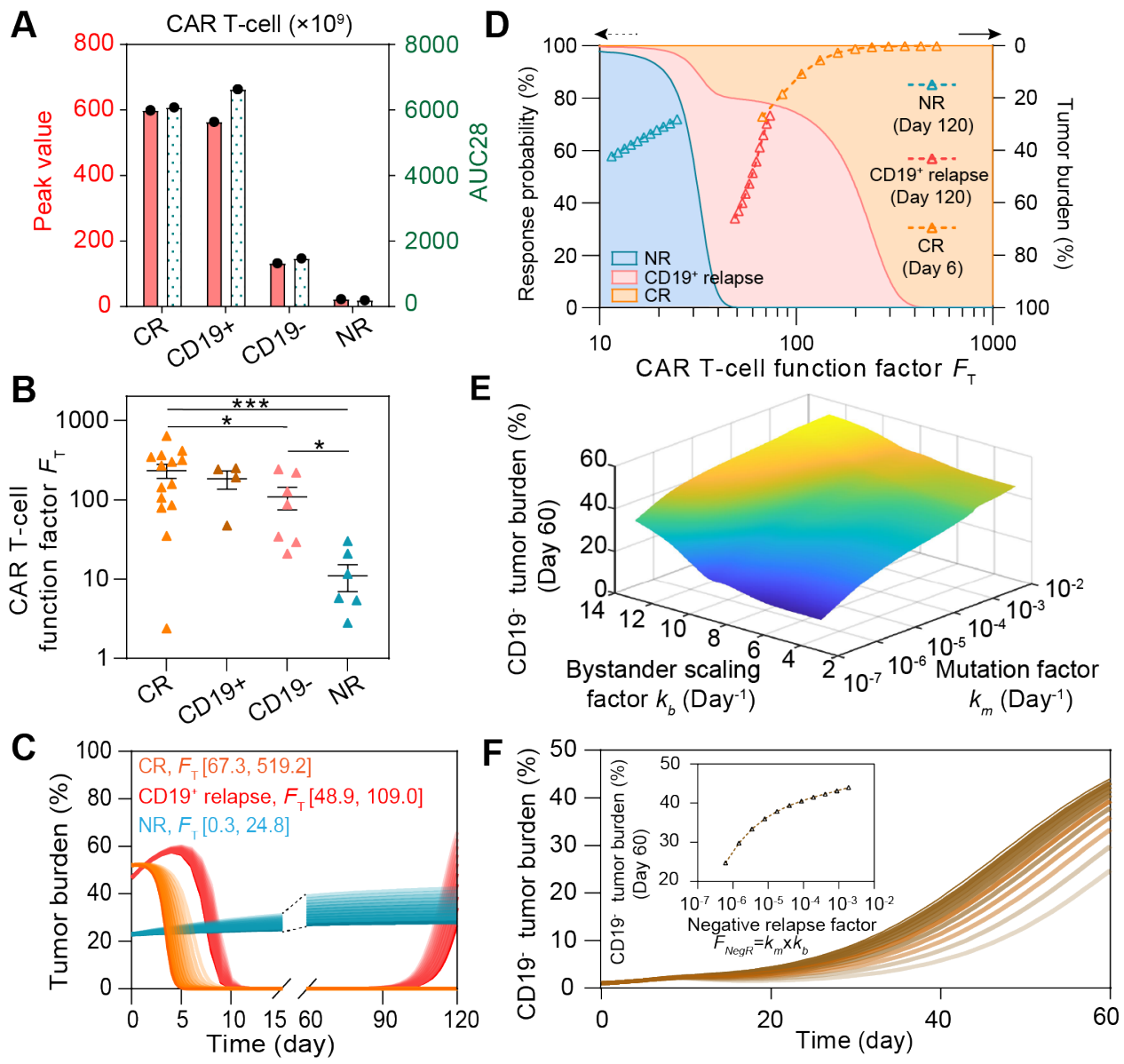

Figure 5. Key determinants in regulating CAR T-cell therapy response. (A) Comparisons of the peak value and AUC28 of CAR T-cell, and (B) CAR T-cell function factors $F_{\mathrm{T}}$ across patients of different responses. Error bars in $\mathrm{B}$ are mean \pm stand error of mean (SEM). (C) Variations of tumor burden as $F_{\mathrm{T}}$ changes. (D) Variation of the response probability as $F_{\mathrm{T}}$ changes (left y-axis) and tumor burden under $F_{\mathrm{T}}$ in $\mathbf{C}$ (right y-axis). For a certain $F_{\mathrm{T}}$, the response probabilities of different responses are represented by different colors (blue for NR, red for CD19 ${ }^{+}$relapse, orange for $\mathrm{CR}$ ) on the direction of $\mathrm{y}$-axis, the sum of the response probabilities is $100 \%$. As $F_{\mathrm{T}}$ changes, areas with different colors are generated. (E) Variations of CD19- tumor burden as the bystander scaling factor $k_{\mathrm{b}}$ and mutation factor $k_{\mathrm{m}}$ change. (F) Variations of CD19- tumor burden as the negative relapse factor $F_{\mathrm{NegR}}$ changes. $P$-values were calculated using Welch's t-test. ${ }^{*} \mathrm{p}<0.05$, $* * * \mathrm{p}<0.001$. 

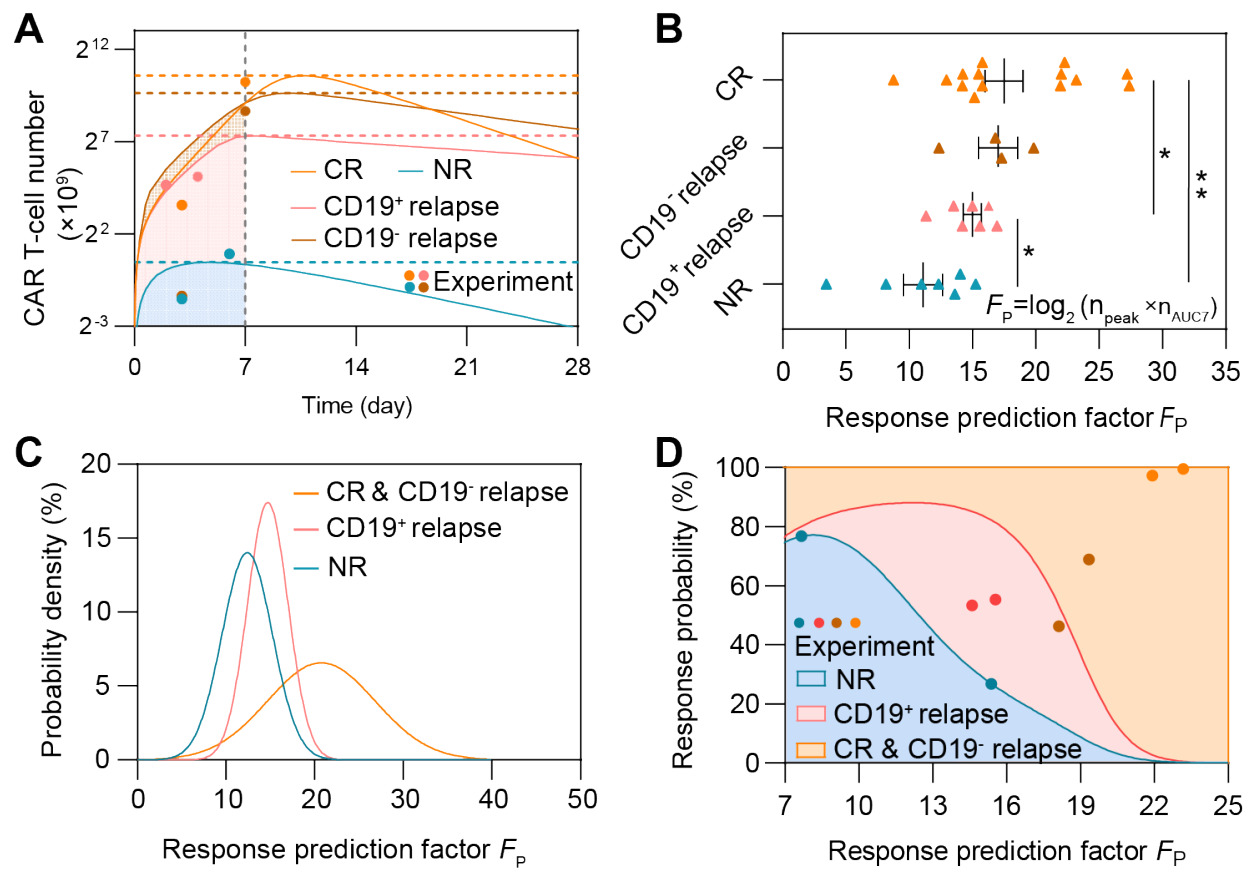

Figure 6. Prediction of CAR T-cell therapy response based on the peak value and AUC7 of CAR T-cells. (A) Variations of CAR T-cell number of typical patient groups with different responses (Group 8 of CR, Group 1 of CD19- relapse, Group 7 of CD19+ relapse, and Group 1 of NR). (B) Comparisons of the response prediction factor $F_{\mathrm{P}}$. Error bars are mean $\pm \mathrm{SEM}$. (C) Probability density of different responses as $F_{\mathrm{P}}$ changes. (D) Variations of response probability as $F_{\mathrm{P}}$ changes. For a certain $F_{\mathrm{T}}$, the response probabilities of different responses are represented by different colors (blue for $\mathrm{NR}$, red for $\mathrm{CD} 19^{+}$relapse, orange for CR\&CD19- relapse) on the direction of $\mathrm{y}$-axis, the sum of the response probabilities is $100 \%$. As $F_{\mathrm{T}}$ changes, areas with different colors are generated. The blue, red, brown, and orange dots represent experimental results of NR, CD19 ${ }^{+}$relapse, CD19- relapse and CR patients respectively to validate prediction ability. $P$-values were calculated using Student's or Welch's t-test. ${ }^{*} \mathrm{p}<0.05,{ }^{*} \mathrm{p}<0.01$. 
medRxiv preprint doi: https://doi.org/10.1101/2021.09.21.21263913; this version posted September 23, 2021. The copyright holder for this preprint (which was not certified by peer review) is the author/funder, who has granted medRxiv a license to display the preprint in perpetuity.

It is made available under a CC-BY-NC-ND 4.0 International license .
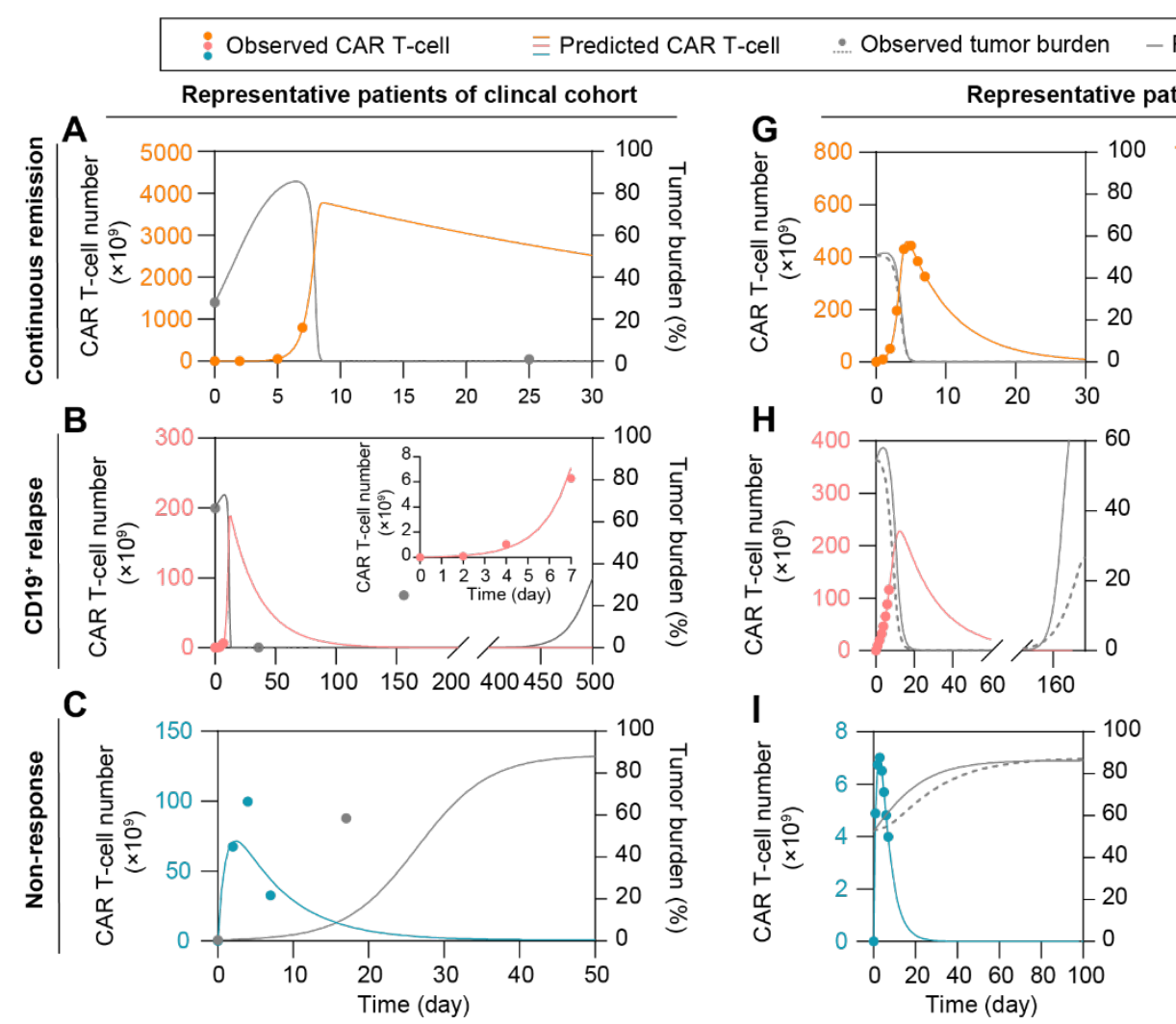

Predicted tumor burden
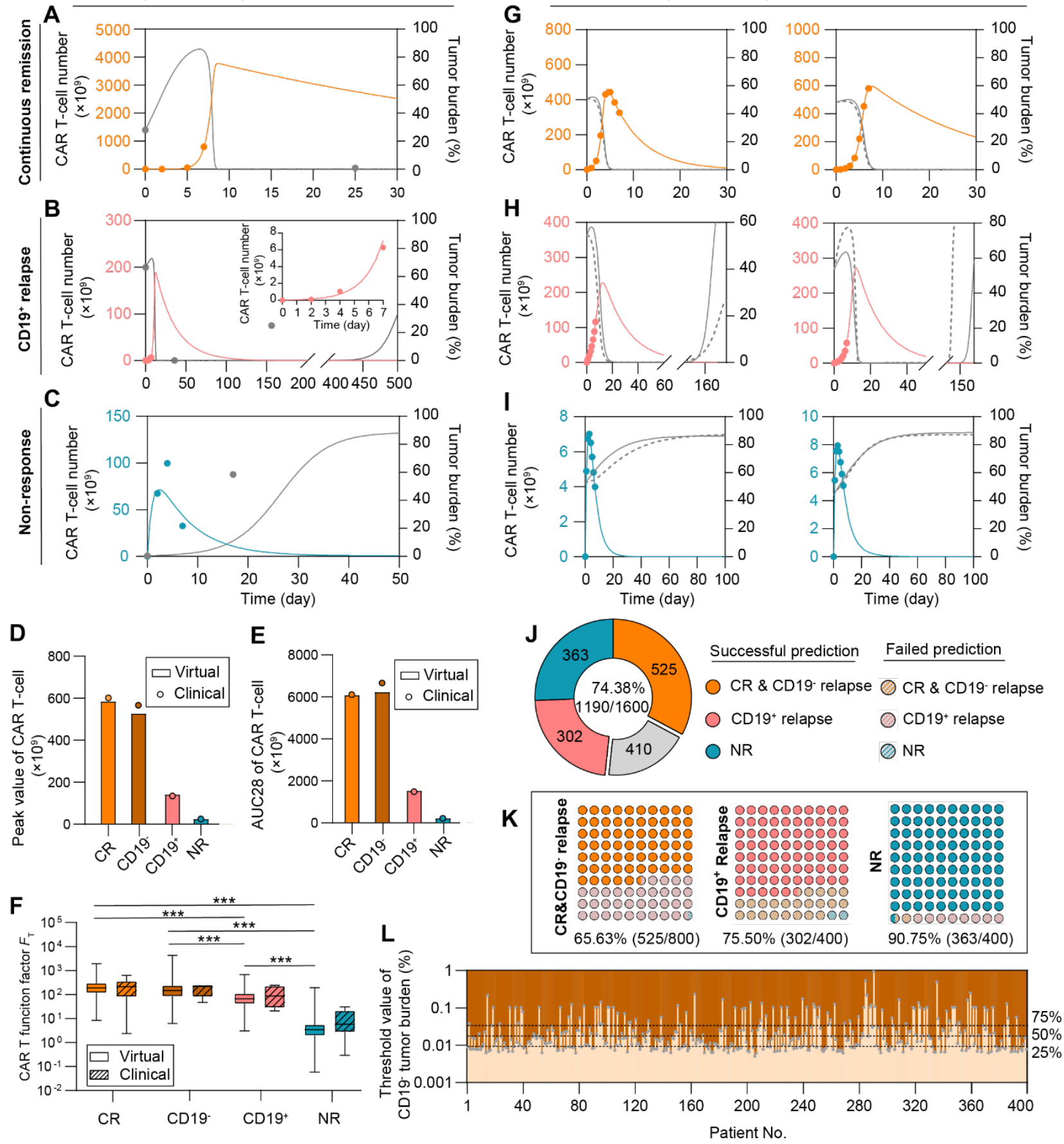

Figure 7. Prediction of patient responses to CAR T-cell therapy based on the CAR T-cell dynamics within first 7 days of treatment. (A-C) Prediction results based on clinical patients of CR (A), CD19 $9^{+}$relapse (B), and NR (C). The minor graph in B shows CAR T-cell dynamics observed and predicted in the first 7 days in a smaller y-axis scale for better display. (D) Median peak value and (E) AUC28 of CAR T-cell of virtual cohort patients and comparisons with clinical cohort patient data. (F) CAR T-cell function factors of virtual patients and comparisons with clinical data. No significant differences between virtual and clinical patients of the same response, 
medRxiv preprint doi: https://doi.org/10.1101/2021.09.21.21263913; this version posted September 23, 2021. The copyright holder for this preprint (which was not certified by peer review) is the author/funder, who has granted medRxiv a license to display the preprint in perpetuity.

It is made available under a CC-BY-NC-ND 4.0 International license .

and between CR and CD19- relapse patients. Whiskers of boxplots are min to max value. (G-I) Real-time prediction results based on virtual patient cohorts. The prediction method predicted the CR $(\mathbf{G})$, CD $19^{+}$relapse $(\mathbf{H})$ and NR (I) of CAR T-cell therapy as observed. (J) Overall prediction accuracy (74.38\%). (K) Prediction accuracy of different response: $65.63 \%$ for CR \& CD19relapse, $75.50 \%$ for $\mathrm{CD} 19^{+}$relapse, and $90.75 \%$ for NR. (L) Threshold values of initial CD19tumor burden to induce CD19- relapse. Dotted lines indicate the values of initial CD19- tumor burden with the occurrence probability $(25 \%, 50 \%, 75 \%)$ of $\mathrm{CD}^{-} 9^{-}$relapse obtained from population level statistics. $P$-values were calculated using Student's or Welch's t-test. ***p $<0.001$. 
medRxiv preprint doi: https://doi.org/10.1101/2021.09.21.21263913; this version posted September 23, 2021. The copyright holder for this preprint (which was not certified by peer review) is the author/funder, who has granted medRxiv a license to display the preprint in perpetuity.

It is made available under a CC-BY-NC-ND 4.0 International license .

Table 1. Estimated parameters and initial values of CAR T-cell and B-ALL cell.

\begin{tabular}{|c|c|c|c|c|c|c|c|}
\hline Parameter & Description & Unit & CR* & $\mathrm{NR}^{*}$ & $\begin{array}{l}\mathrm{CD19}^{+} \\
\text {relapse }\end{array}$ & $\begin{array}{l}\mathrm{CD19}^{-} \\
\text {relapse }\end{array}$ & Reference \\
\hline$\overline{r_{\mathrm{P}}}$ & $\begin{array}{l}\text { Growth rate of } \mathrm{CD} 19^{+} \mathrm{B}- \\
\text { ALL cell }\end{array}$ & Day $^{-1}$ & 0.069 & 0.080 & 0.21 & 0.071 & $(45,46)$ \\
\hline$r_{\mathrm{TA}}$ & $\begin{array}{l}\text { Growth rate of activated } \\
\text { CAR T-cell }\end{array}$ & Day $^{-1}$ & 1.62 & 0.99 & 0.99 & 1.5 & $(13,47)$ \\
\hline$l_{\mathrm{TA}}$ & $\begin{array}{l}\text { Apoptosis rate of } \\
\text { activated CAR T-cell }\end{array}$ & Day $^{-1}$ & 0.12 & 0.55 & 0.12 & 0.11 & $(48,49)$ \\
\hline$l_{\mathrm{TN}}$ & $\begin{array}{l}\text { Apoptosis rate of non- } \\
\text { activated CAR T-cell }\end{array}$ & Day $^{-1}$ & $3 e-5$ & $9.2 \mathrm{e}-4$ & $6 e-7$ & $2 \mathrm{e}-7$ & \\
\hline$n_{\mathrm{C}}$ & $\begin{array}{l}\text { B-ALL cell carrying } \\
\text { capacity }\end{array}$ & & 2939.1 & 6101.58 & 19877.4 & 2585.74 & \\
\hline$e$ & $\begin{array}{l}\text { Killing rate of activated } \\
\text { CAR T-cell }\end{array}$ & Day $^{-1}$ & 22.72 & 6.58 & 20.31 & 19.34 & $(10)$ \\
\hline$K_{\mathrm{P}}$ & $\begin{array}{l}\text { Saturation constant to } \\
\text { CAR - T cell killing rate }\end{array}$ & & 5891.5 & 7067.07 & 1050.19 & 11040.05 & \\
\hline$K_{r}$ & $\begin{array}{l}\text { Saturation constant to } \\
\text { CAR T-cell growth rate }\end{array}$ & & 637.64 & 3431.65 & 1983.64 & 1360.54 & \\
\hline$K_{\mathrm{A}}$ & $\begin{array}{l}\text { Saturation constant to } \\
\text { CAR T-cell activation } \\
\text { rate }\end{array}$ & & 1808.0 & 0.0052 & 54.68 & 11883.73 & \\
\hline$k_{\mathrm{A}}$ & $\begin{array}{l}\text { Activation rate of CAR } \\
\text { T-cell }\end{array}$ & Day $^{-1}$ & 0.65 & 0.31 & 0.44 & 0.58 & \\
\hline$r_{\mathrm{N}}$ & $\begin{array}{l}\text { Growth rate of CD19- B- } \\
\text { ALL cell }\end{array}$ & Day $^{-1}$ & I & / & l & 0.1 & $(45,46)$ \\
\hline$k_{\mathrm{m}}$ & Mutation factor & Day $^{-1}$ & I & I & l & $1.5 \mathrm{e}-7$ & $(50)$ \\
\hline$k_{\mathrm{b}}$ & $\begin{array}{l}\text { Bystander killing scaling } \\
\text { factor }\end{array}$ & & l & l & l & 7.9 & \\
\hline$K_{\mathrm{N}}$ & $\begin{array}{l}\text { Saturation rate of CD19- } \\
\text { B-ALL cell to killing } \\
\text { efficacy }\end{array}$ & & / & / & l & 16956.03 & \\
\hline$n_{\mathrm{P} 0}$ & $\begin{array}{l}\text { Initial value of } \mathrm{CD} 19^{+} \mathrm{B}- \\
\text { ALL cell }\end{array}$ & $\times 10^{9}$ cells & 2200.24 & 589.676 & 1764.25 & 1467.01 & \\
\hline$n_{\mathrm{N} 0}$ & $\begin{array}{l}\text { Initial value of CD19- B- } \\
\text { ALL cell }\end{array}$ & $\times 10^{9}$ cells & I & / & l & 19.89 & $\begin{array}{l}\text { Assumed } \\
(1 \%)\end{array}$ \\
\hline$n_{\mathrm{TN} 0}$ & $\begin{array}{l}\text { Initial value of non- } \\
\text { activated CAR T-cell }\end{array}$ & $\times 10^{9}$ cells & 16.5 & 71.45 & 12.26 & 8.97 & \\
\hline
\end{tabular}

*CR represents continuous remission and NR represents non-response. 


\section{Supplementary Information}

Table S1. Merged clinical data of continuous remission patient groups from individuals

\begin{tabular}{cccl}
\hline Group & Reference & Number of individuals & \multicolumn{1}{c}{ Statistical value } \\
\hline 1 & $(35)$ & 45 & LOESS (local polynomial regression) curve fitting \\
2 & $(25)$ & 14 & First quartile \\
3 & $(25)$ & 14 & Second quartile \\
4 & $(25)$ & 14 & Third quartile \\
5 & $(36)$ & 59 & Median \& geometric mean \\
6 & $(37)$ & 1 & Original (Patient 1) \\
7 & $(38)$ & 8 & Mean \\
8 & $(39)$ & 1 & Original (No. MSK-ALL05) \\
9 & $(40)$ & 4 & BM M1 status (<5\%) \\
10 & $(40)$ & 4 & BM M2 status (5-25\%) \\
11 & $(40)$ & 9 & BM M3 status (>25\%) \\
12 & $(41)$ & 1 & Original (No. MSK-ALL13) \\
13 & $(41)$ & 1 & Original (No. MSK-ALL14) \\
14 & $(41)$ & 1 & Original (No. MSK-ALL13) \\
Total & & 148 & \\
\hline
\end{tabular}

Table S2. Merged clinical data of non-responding patient groups from individuals

\begin{tabular}{cccl}
\hline Group & Reference & Number of individuals & \multicolumn{1}{c}{ Statistical value } \\
\hline 1 & $(35)$ & 8 & LOESS (local polynomial regression) curve fitting \\
2 & $(25)$ & 6 & Mean \\
3 & $(36)$ & 6 & Median \& geometric mean \\
4 & $(42)$ & 1 & Original (Patient 4) \\
5 & $(42)$ & 1 & Original (Patient 5) \\
6 & $(42)$ & 1 & Original (Patient 8) \\
7 & $(42)$ & 1 & Original (Patient 9) \\
Total & & 24 & \\
\hline
\end{tabular}

Table S3. Merged clinical data of CD19 ${ }^{+}$relapse patient groups from individuals

\begin{tabular}{cccl}
\hline Group & Reference & Number of individuals & \multicolumn{1}{c}{ Statistical value } \\
\hline 1 & $(35)$ & 14 & LOESS (local polynomial regression) curve fitting \\
2 & $(39)$ & 1 & Original (No. MSK-ALL04) \\
3 & $(42)$ & 1 & Original (Patient 1) \\
4 & $(42)$ & 1 & Original (Patient 2) \\
5 & $(42)$ & 1 & Original (Patient 3) \\
6 & $(42)$ & 1 & Original (Patient 6) \\
7 & $(42)$ & 1 & Original (Patient 7) \\
Total & & 20 & \\
\hline
\end{tabular}

Table S4. Merged clinical data of CD19- relapse patient groups from individuals

\begin{tabular}{cccl}
\hline Group & Reference & Number of individuals & \multicolumn{1}{c}{ Statistical value } \\
\hline 1 & $(35)$ & 14 & LOESS (local polynomial regression) curve fitting \\
2 & $(37)$ & 1 & Original (Patient 2) \\
3 & $(43)$ & 1 & Original (Case 1) \\
4 & $(43)$ & 1 & Original (Case 2) \\
Total & & 17 & \\
\hline
\end{tabular}



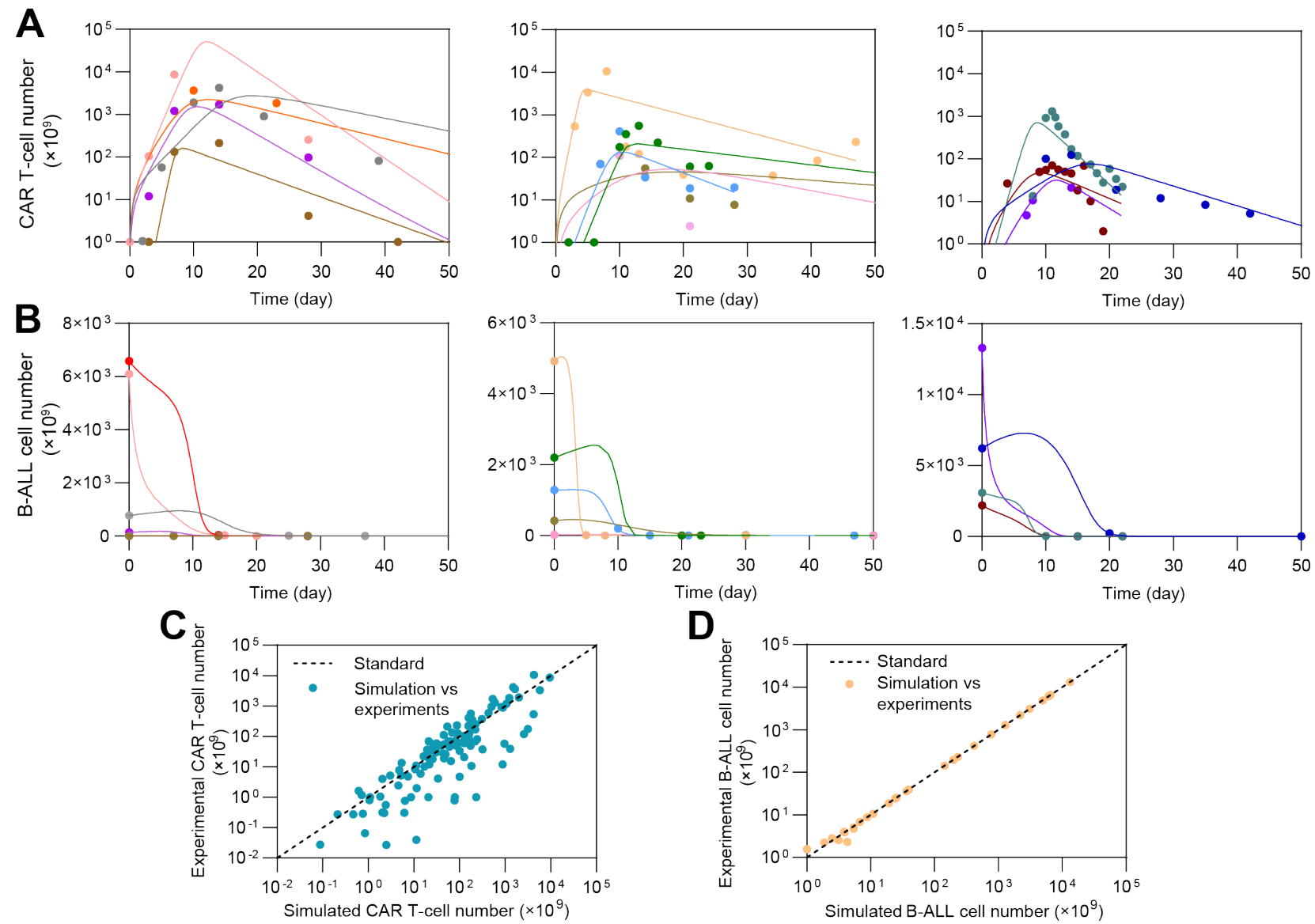

Figure S1. Individual fitting results of continuous remission patients. (A\&B) Fitting results of CAR T-cell (A) and B-ALL cell (B) dynamics. The dots represent the experimental data and the lines represent the fitted curves. (C\&D) Simulated versus experimental results of CAR T-cell (C) and B-ALL cell (D). Each dot represents the comparison between experimental CAR T-cell number and corresponding simulated result on the same day, and the dash lines represent the standard curves where simulated results are equal to experimental results. 

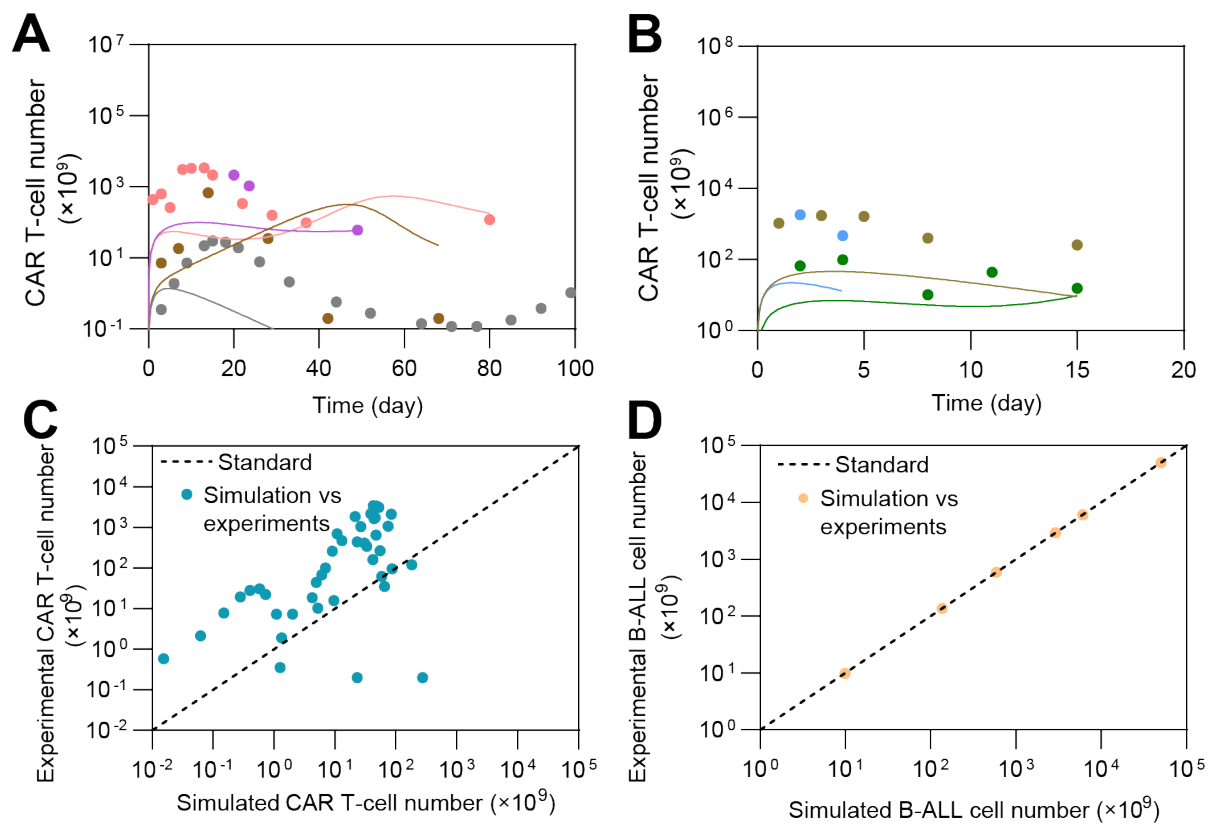

Figure S2. Individual fitting results of non-responding patients. (A\&B) Fitting results of CAR T-cell dynamics. The dots represent the experimental data and the lines represent the fitted curves. (C\&D) Simulated versus experimental results of CAR T-cell (C) and B-ALL cell (D). Each dot represents the comparison between experimental CAR T-cell number and corresponding simulated result on the same day, and the dash lines represent the standard curves where simulated results are equal to experimental results.

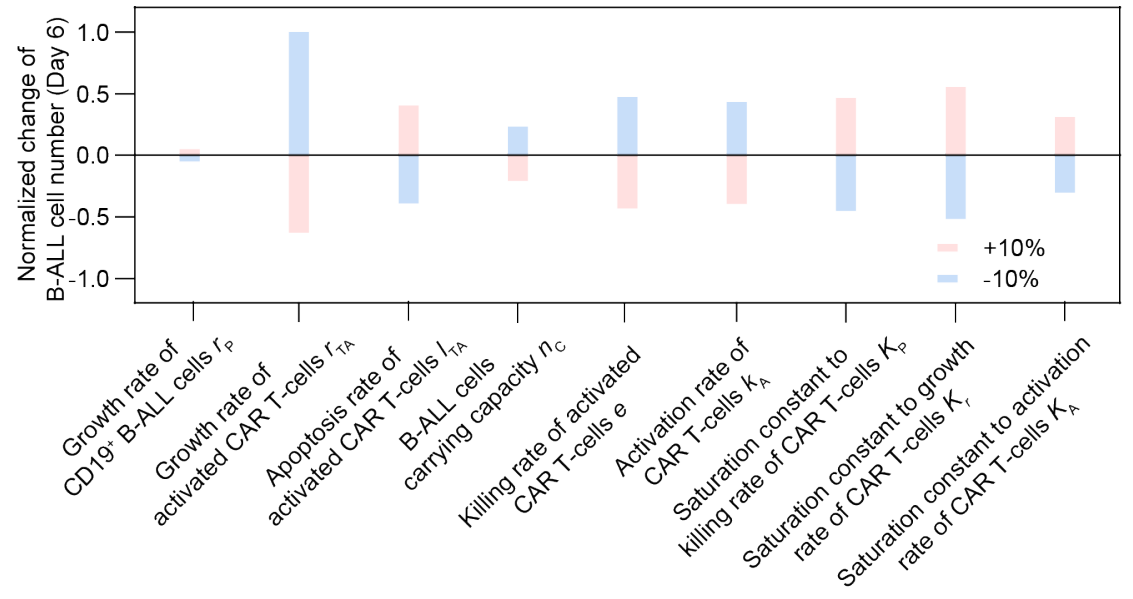

Figure S3. Sensitivity analysis of different CAR T-cell parameters in the computational model. 

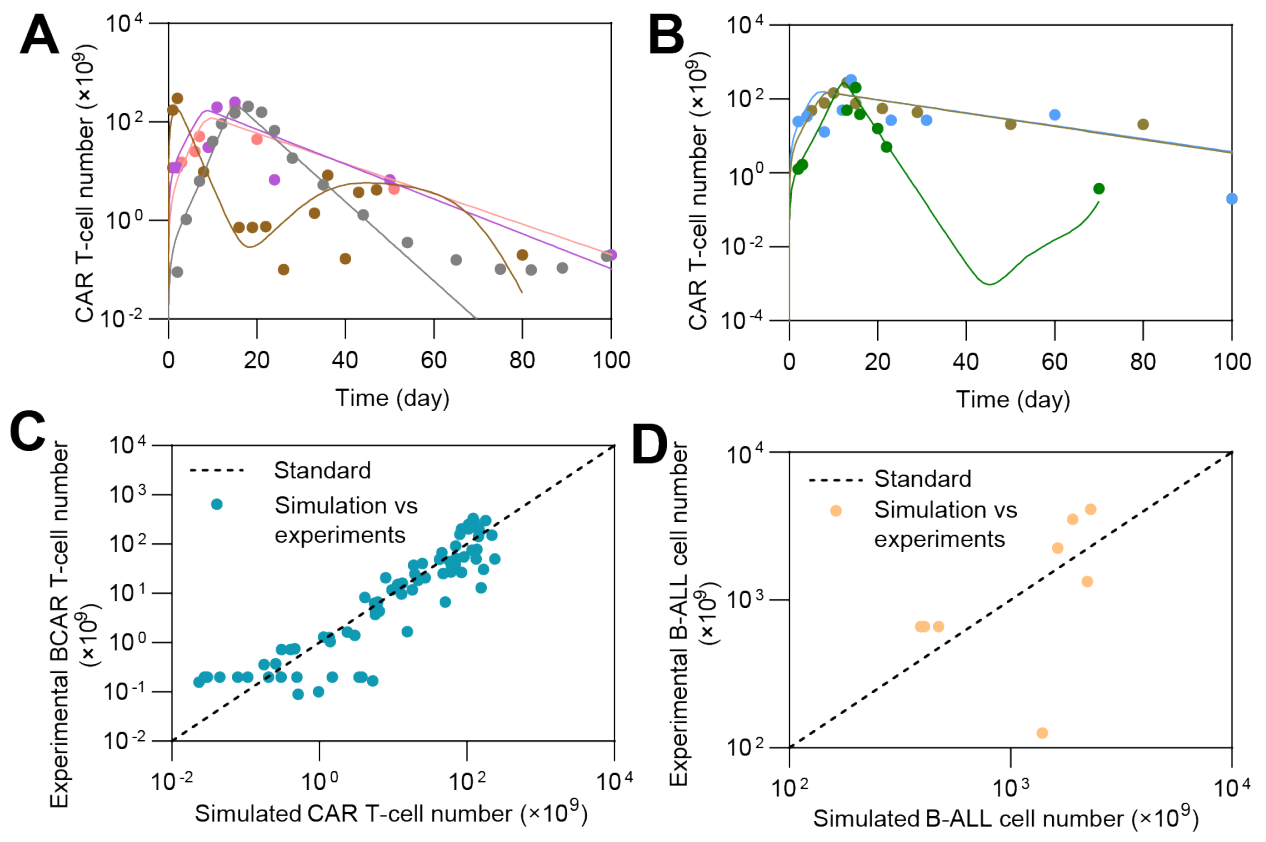

Figure S4. Individual fitting results of $\mathrm{CD}^{+}{ }^{+}$relapse patients. (A\&B) Fitting results of CAR T-cell dynamics. The dots represent the experimental data and the lines represent the fitted curves. (C\&D) Simulation versus experimental results of CAR T-cells (C) and B-ALL cells (D). Each dot represents the comparison between experimental CAR T-cell number and corresponding simulated result on the same day, and the dash lines represent the standard curves where simulated results are equal to experimental results.
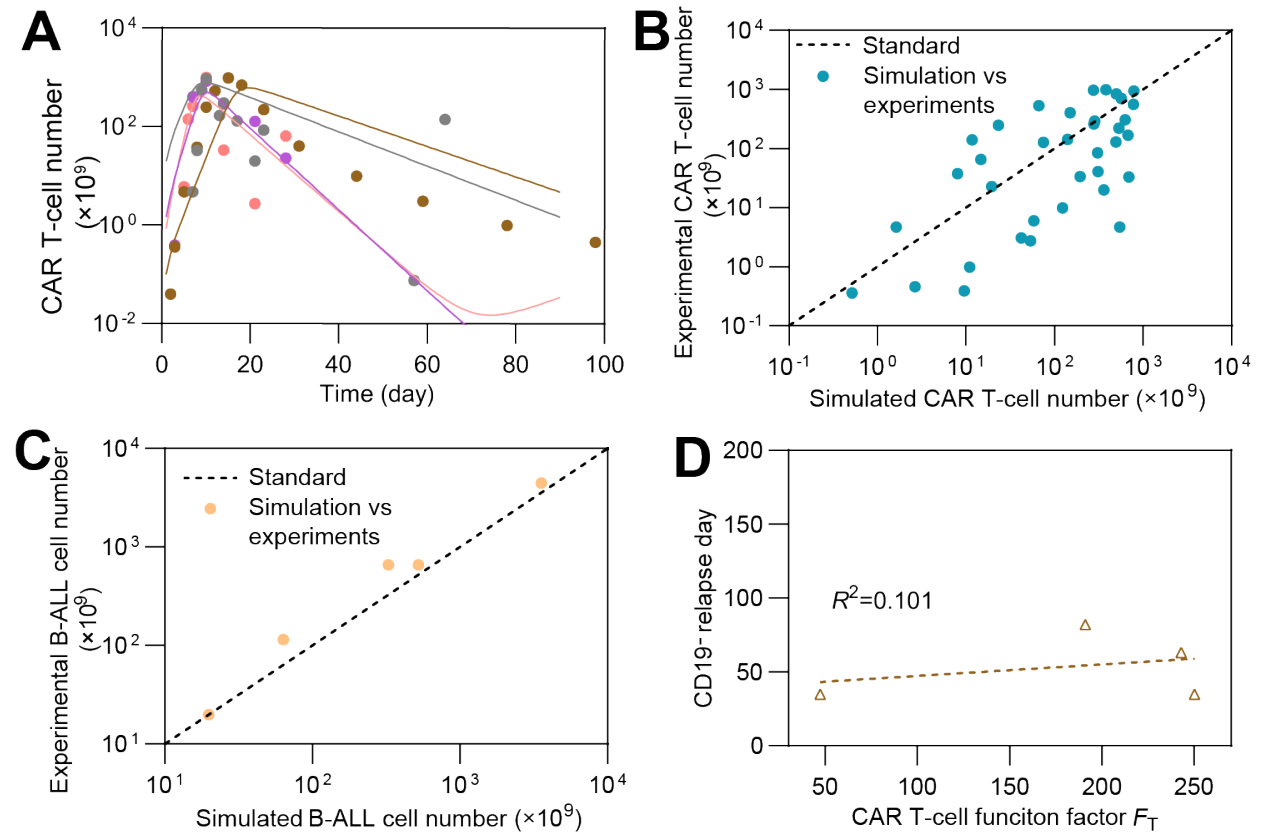

Figure S5. Fitting results of CD19- relapse patients. (A) Individual fitting results of CAR T-cell dynamics. The dots represent the experimental data and the lines represent the fitted curves. (B\&C) Simulation vs. experimental results of CAR T-cell $(\mathbf{B})$ and $(\mathbf{C})$ B-ALL cell. Each dot represents the comparison between experimental CAR T-cell number and corresponding simulated result on 
medRxiv preprint doi: https://doi.org/10.1101/2021.09.21.21263913; this version posted September 23, 2021. The copyright holder for this preprint (which was not certified by peer review) is the author/funder, who has granted medRxiv a license to display the preprint in perpetuity.

It is made available under a CC-BY-NC-ND 4.0 International license .

the same day, and the dash lines represent the standard curves where simulated results are equal to experimental results. (D) The relationship between CAR T-cell function factor $F_{\mathrm{T}}$ of clinical patient and CD19- relapse day.

A

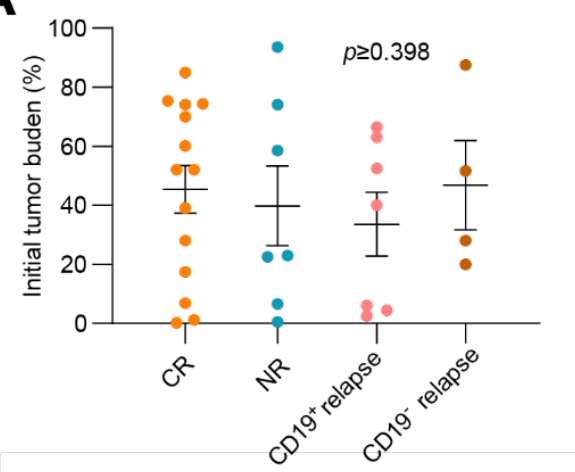

C

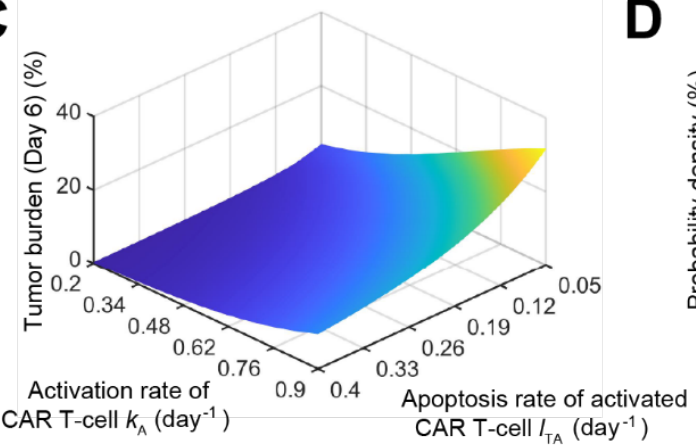

B
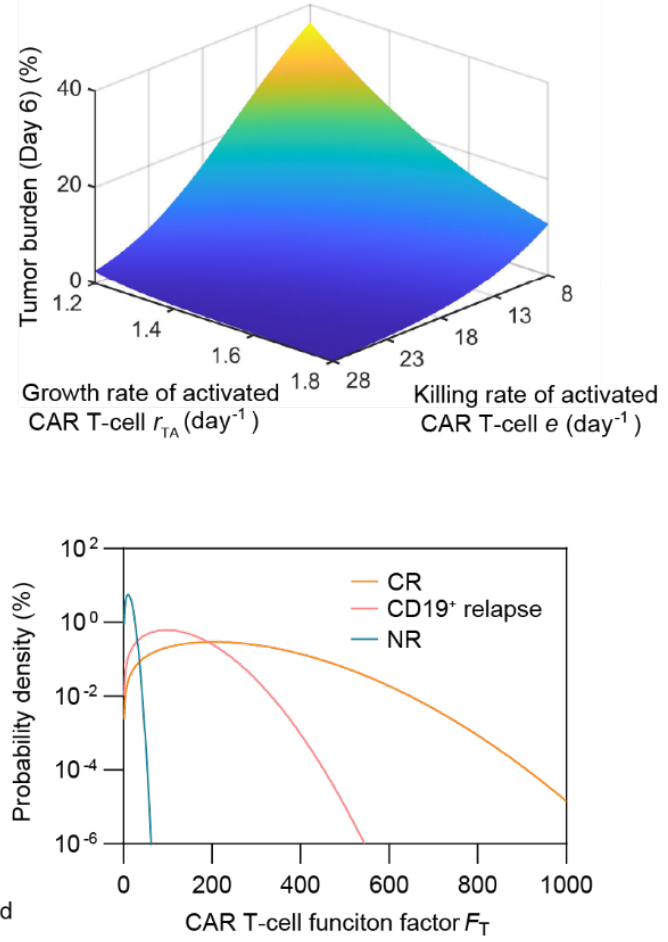

Figure S6. The relationship between CAR T-cell function factor $F_{\mathrm{T}}$ and CAR T-cell therapy outcome. (A) Initial tumor burden in patients of different responses, showing no significant difference $(p \geq 0.398)$. The dots represent the experimental data and the error bars represent the fitted results. Error bars are mean \pm SEM. (B\&C) Effects of $F_{\mathrm{T}}$ related parameters to therapeutic efficacy: variations of tumor burden at day 6 (day of CAR T-cell at peak) as CAR T-cell growth rate $r_{\mathrm{TA}}$ and killing rate $e(\mathbf{B})$, and activation rate $k_{\mathrm{A}}$ and apoptosis rate $l_{\mathrm{TA}}(\mathbf{C})$ change. The parameters are based on population-level continuous remission patients. (D) Probability density of different responses as $F_{\mathrm{T}}$ changes.
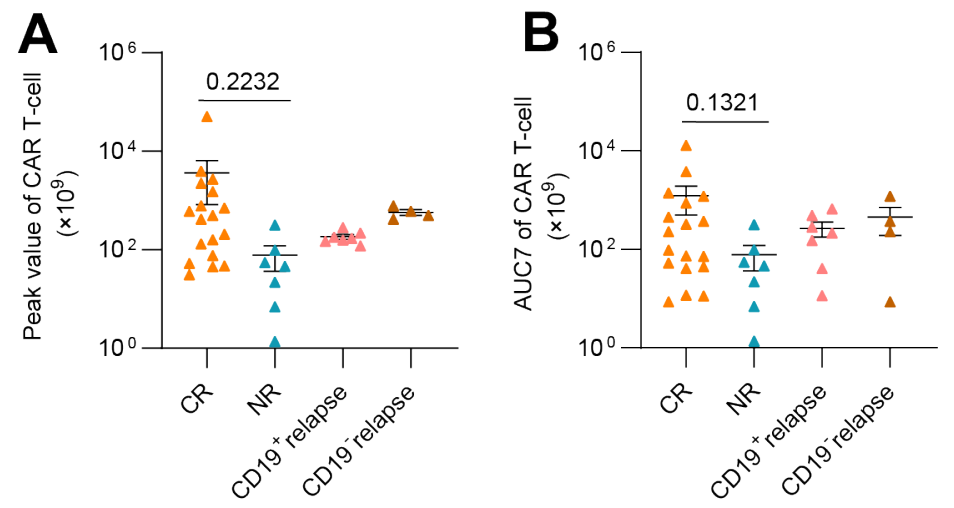

Figure S7. (A) Peak value and (B) AUC7 of CAR T-cell of different responses to CAR T-cell therapy. Dots and error bars are based on simulated results. Non-significant difference exists 
medRxiv preprint doi: https://doi.org/10.1101/2021.09.21.21263913; this version posted September 23, 2021. The copyright holder for this preprint (which was not certified by peer review) is the author/funder, who has granted medRxiv a license to display the preprint in perpetuity.

It is made available under a CC-BY-NC-ND 4.0 International license .

between groups for each parameter. Error bars are mean \pm SEM. $P$-values were calculated using Welch's t-test.
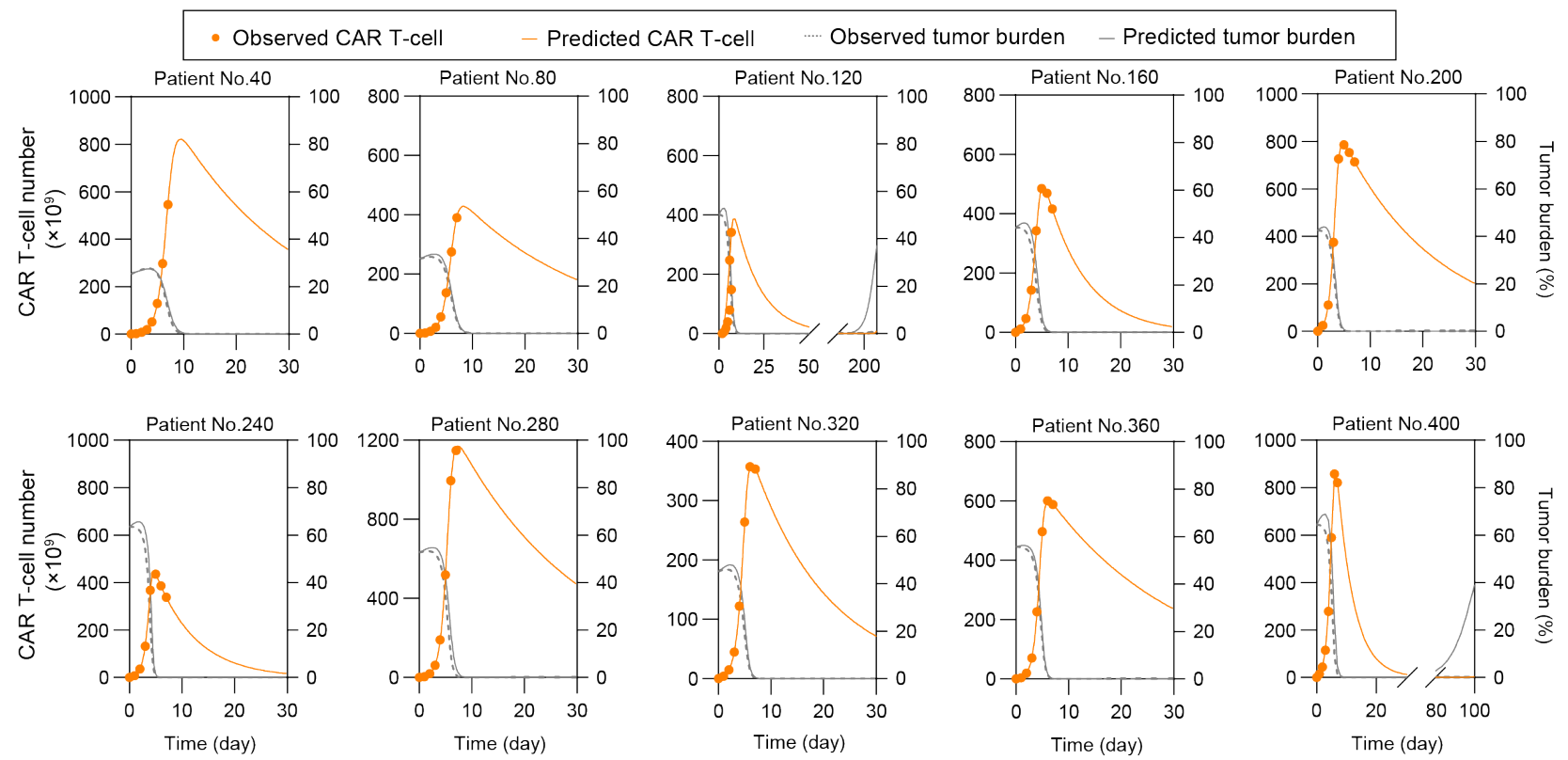

Figure S8. Part of real-time prediction results of CR\&CD19- relapse based on virtual patient cohorts. Repetitive virtual patients were chosen at an interval of 40 from the 400 tested patients.
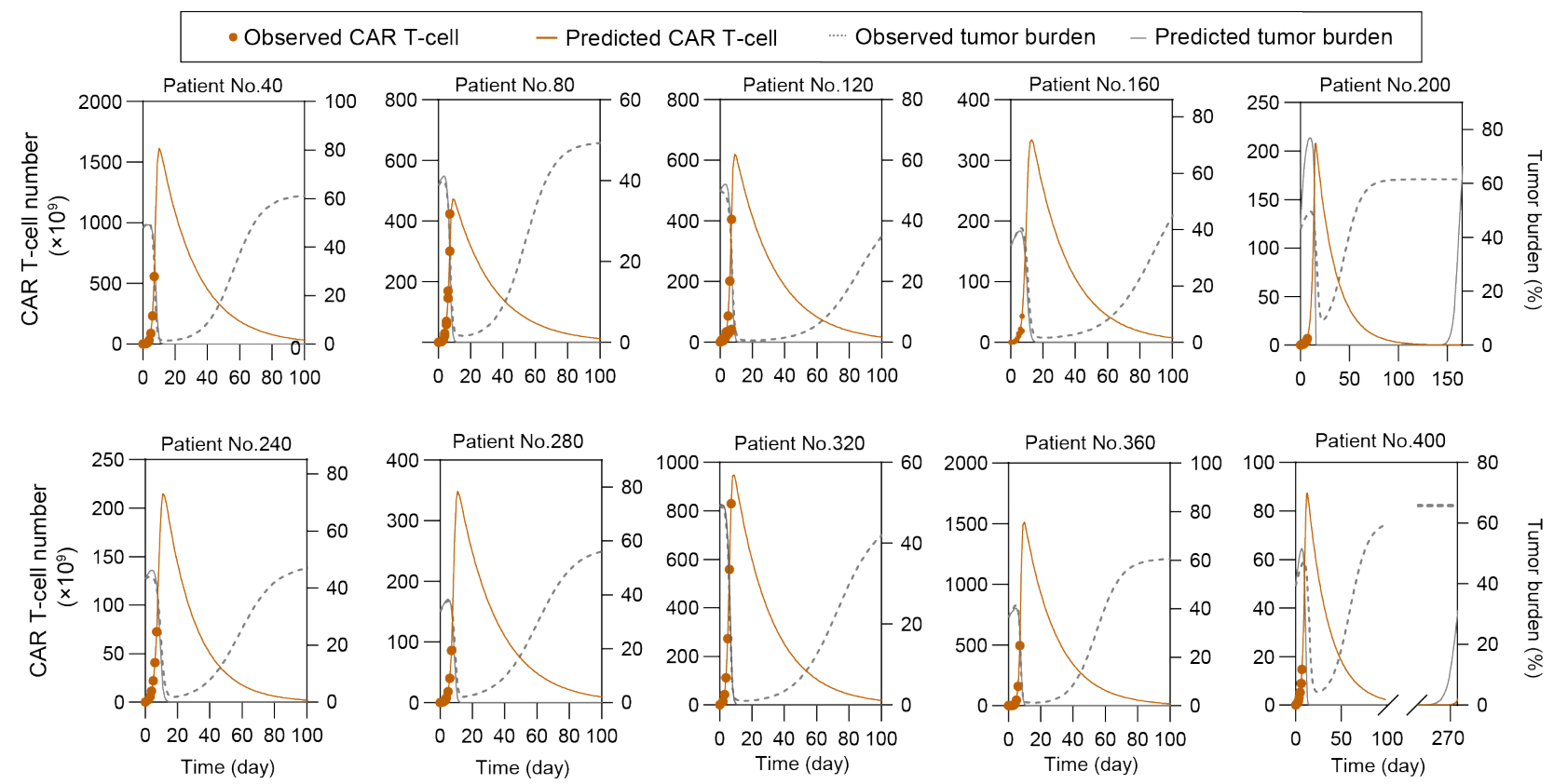

Figure S9. Part of real-time prediction results of CD19- relapse based on virtual patient cohorts. Repetitive virtual patients were chosen at an interval of 40 from the 400 tested patients. 
medRxiv preprint doi: https://doi.org/10.1101/2021.09.21.21263913; this version posted September 23, 2021. The copyright holder for this preprint (which was not certified by peer review) is the author/funder, who has granted medRxiv a license to display the preprint in perpetuity.

It is made available under a CC-BY-NC-ND 4.0 International license .

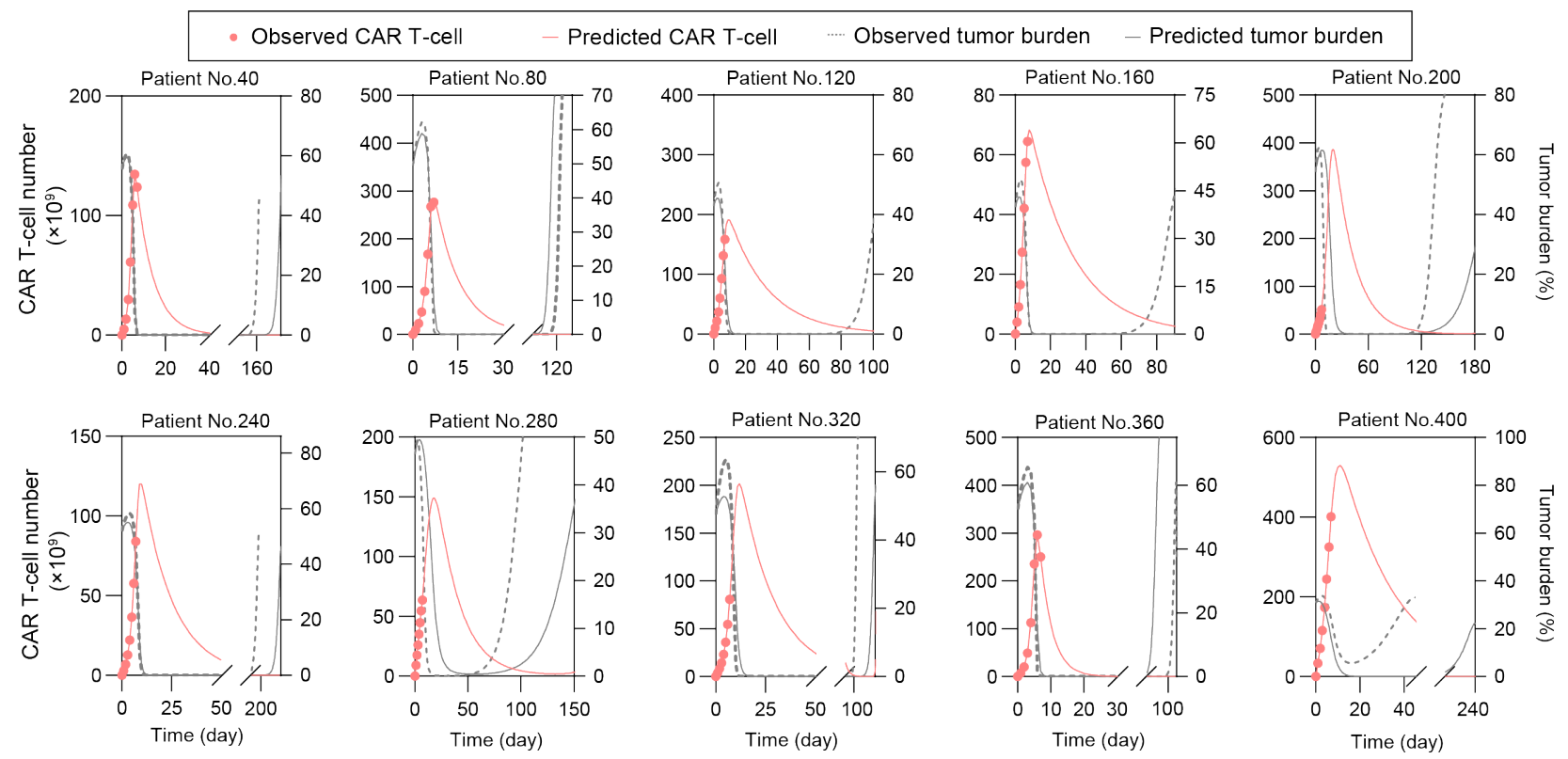

Figure S10. Part of real-time prediction results of $\mathrm{CD}^{+} 9^{+}$relapse based on virtual patient cohorts. Repetitive virtual patients were chosen at an interval of 40 from the 400 tested patients.
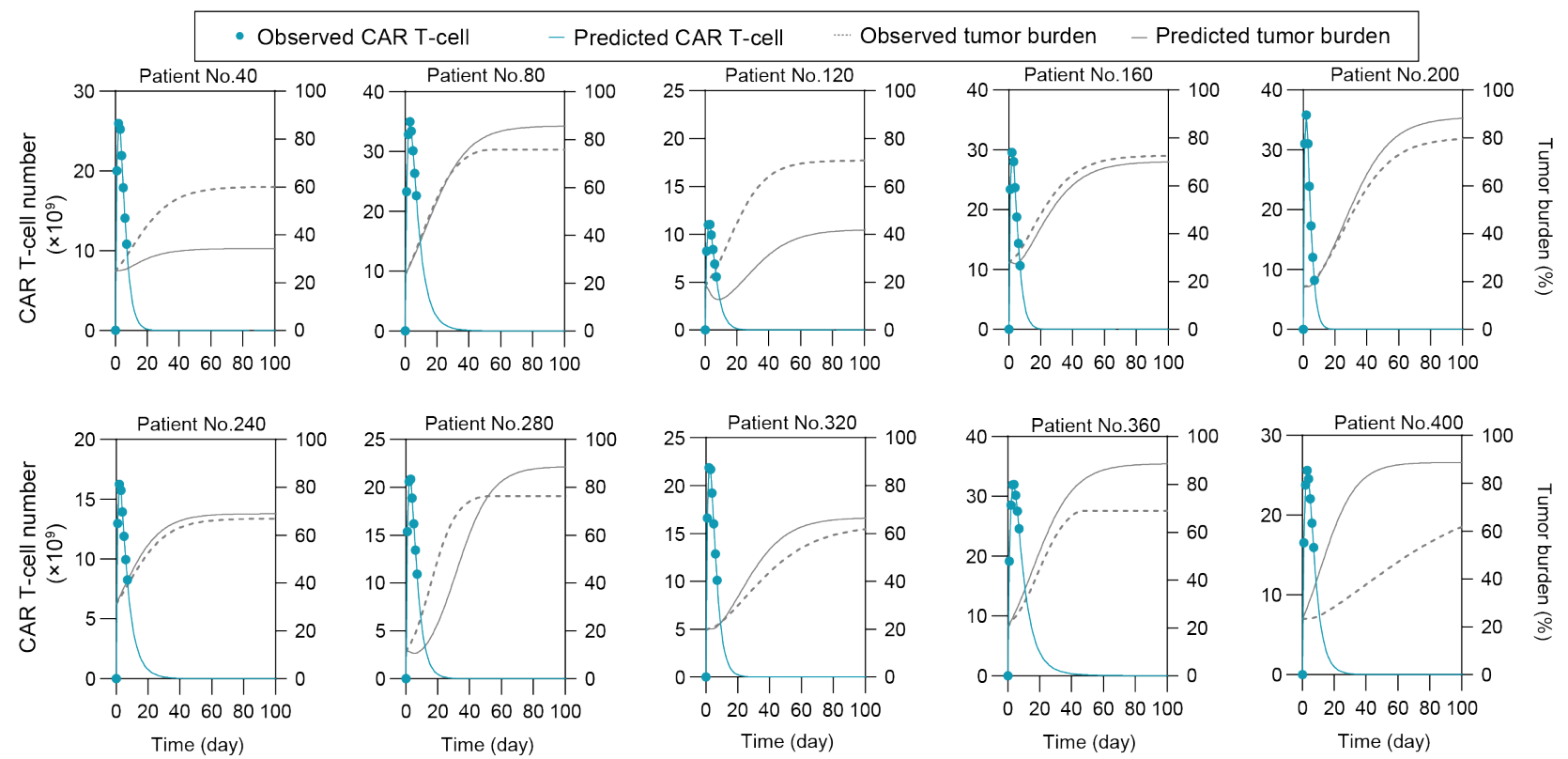

Figure S11. Part of real-time prediction results of non-response based on virtual patient cohorts. Repetitive virtual patients were chosen at an interval of 40 from the 400 tested patients. 
medRxiv preprint doi: https://doi.org/10.1101/2021.09.21.21263913; this version posted September 23, 2021. The copyright holder for this preprint (which was not certified by peer review) is the author/funder, who has granted medRxiv a license to display the preprint in perpetuity.

It is made available under a CC-BY-NC-ND 4.0 International license .

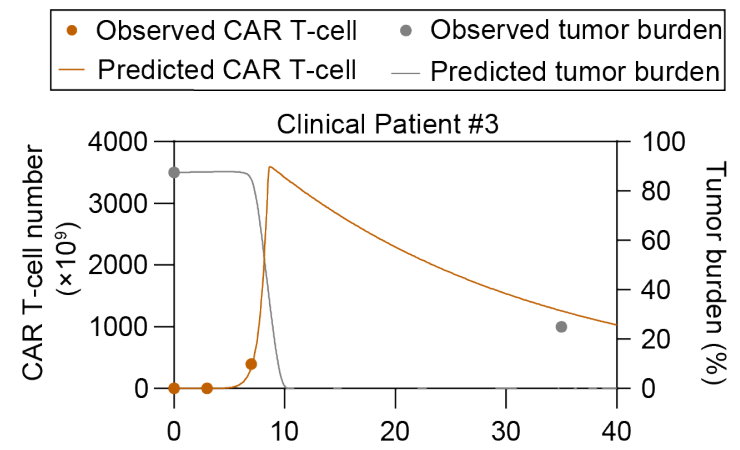

Figure S12. Prediction results based on clinical patient of CD19- relapse.
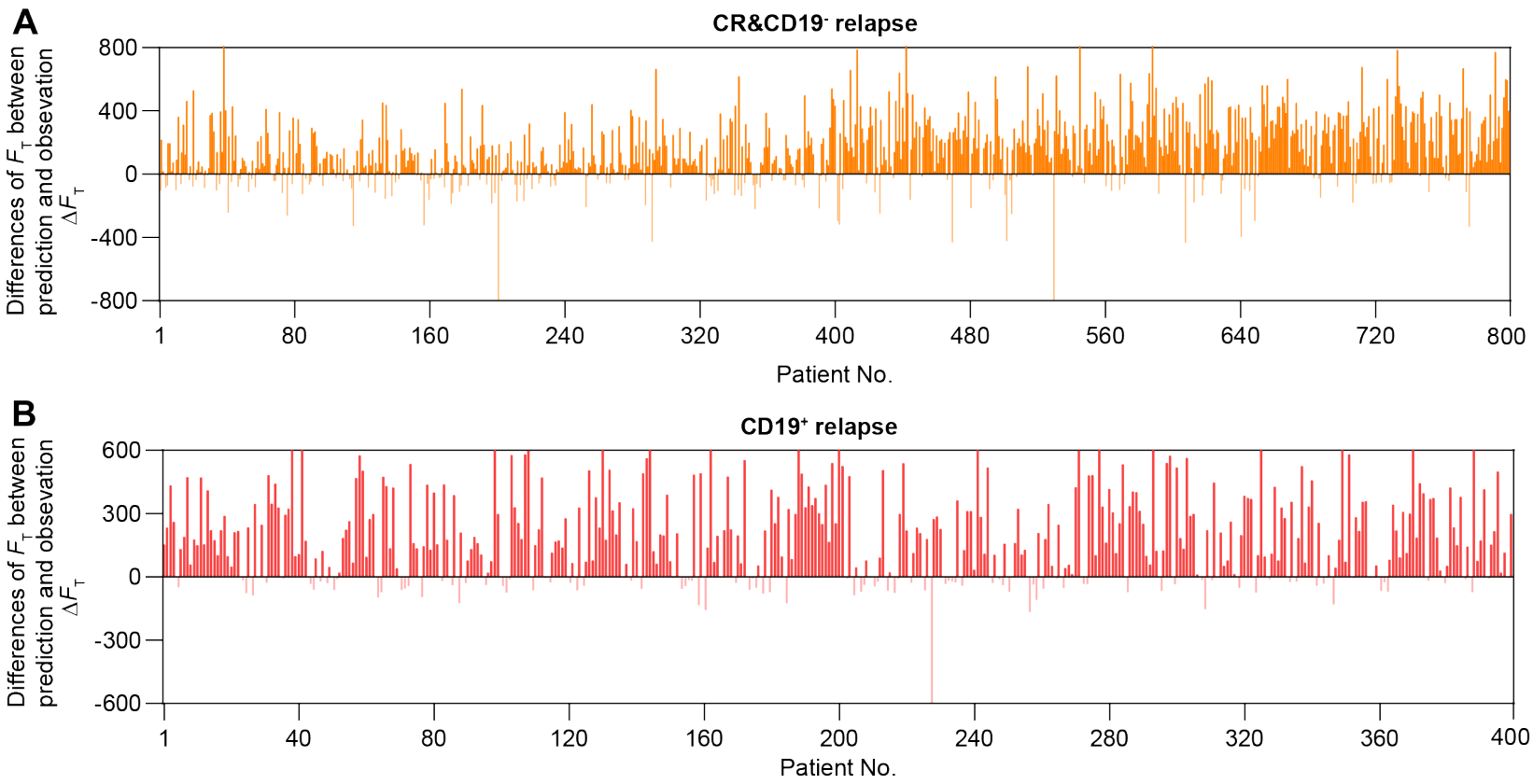

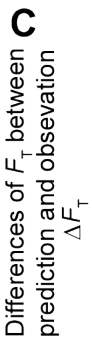

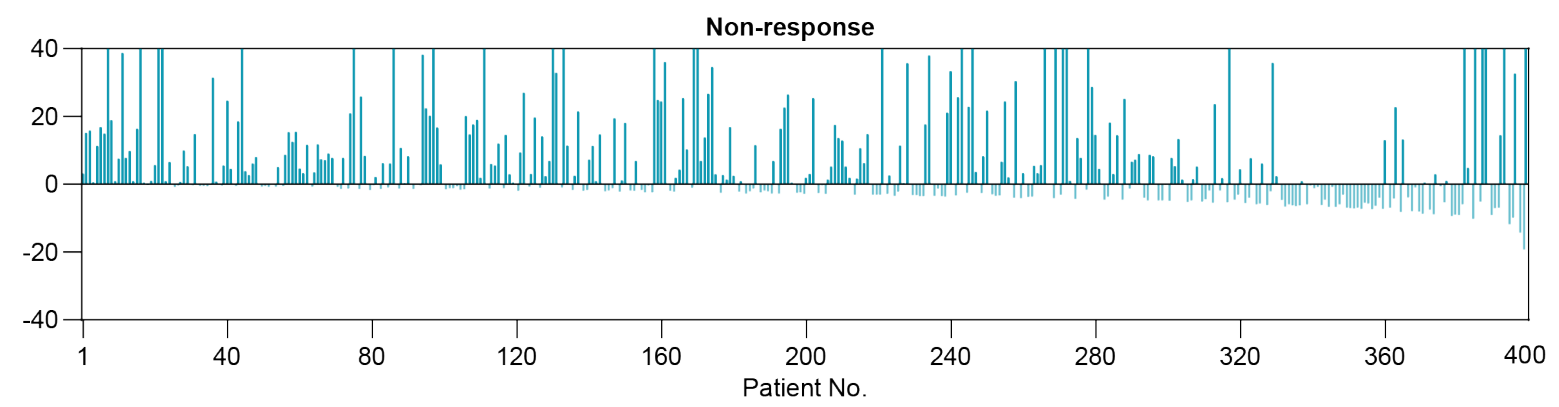

Figure S13. Differences of $F_{T}$ between prediction and observation $\Delta F_{T}$ of CR\&CD19- ${ }^{-}$relapse (A), CD19 ${ }^{+}$relapse (B) and non-response (C) of the 1600 tested virtual patients. 


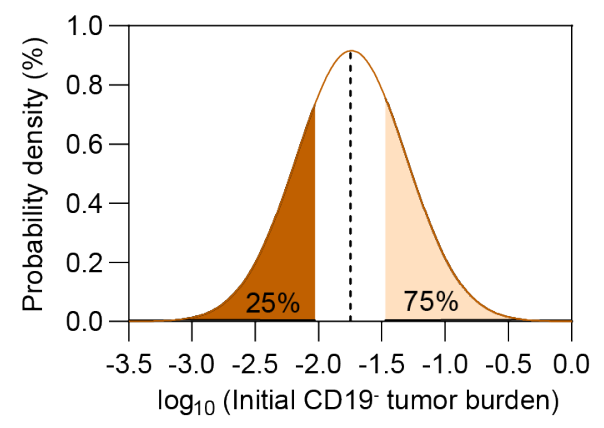

Figure S14. Probability density of the occurrence of CD19- relapse of the 400 tested virtual patients as the value of initial CD19- tumor burden changes.

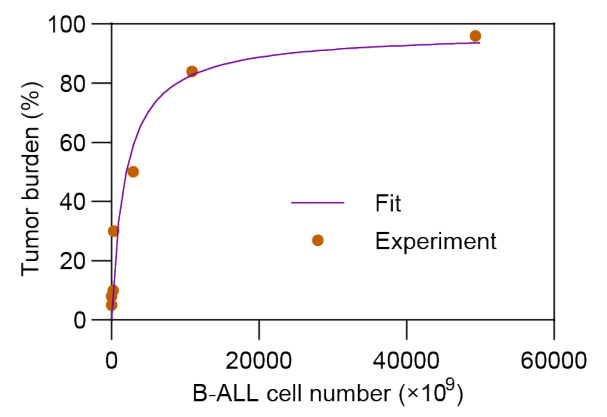

Figure S15. Relationship between the number of B-ALL cell and tumor burden (\%). The fitting curve is based on the clinical pre-treatment tumor burdens (Table 1 of ref. (25)) and absolute numbers of B-ALL cells (Figure 1G of ref.(25)) of MRD`- patients. 